\title{
EL PROBLEMA DE LA DETERMINACIÓN DEL NEXO CAUSAL EN LA RESPONSABILIDAD CIVIL POR DAÑOS MEDIOAMBIENTALES: DE LA CERTEZA CAUSAL A LA TEORÍA DE LA CAUSALIDAD COMPLEJA ${ }^{1}$
}

\author{
THE PROBLEM OF DETERMINING THE CAUSATION IN CIVIL LIABILITY FOR \\ ENVIRONMENTAL DAMAGE: FROM CAUSAL CERTAINTY TO THE THEORY OF \\ COMPLEX CAUSALITY
}

Por Amanda Kalil (*)

\begin{abstract}
Resumen: Este trabajo tiene por objetivo investigar la determinación del nexo de causalidad en la responsabilidad civil por daños ambientales y la necesidad de adaptar la prueba de la relación causal a las nuevas exigencias impuestas por el fenómeno de la "causalidad compleja" del daño ambiental. El estudio enfoca el tratamiento conferido por el ordenamiento jurídico y por los tribunales españoles, destacando el contexto actual de la sociedad de riesgo. Por tanto, el estudio presenta las teorías explicativas del nexo de causalidad, destaca el concepto de la causalidad compleja, así como los obstáculos existentes en orden a la identificación y comprobación de la "causalidad ambiental". Asimismo, se analizan los obstáculos existentes para la identificación y comprobación de la causalidad ambiental, como la multiplicidad de agentes, la concurrencia de causas y los daños continuados, entre otros. Esta investigación presenta también las propuestas existentes en el derecho comparado y sugiere, por lo tanto, la incorporación de una serie de teorías dirigidas a resolver los problemas presentados en la prueba del nexo causal y, en consecuencia, conseguir que la responsabilidad civil sea un instrumento eficaz de protección y reparación de los daños medioambientales.
\end{abstract}

Palabras Clave: Responsabilidad civil; daño ambiental; nexo causal; prueba.

\begin{abstract}
The objective of this work is to investigate the determination of the causation in civil liability for environmental damage and the need to adapt the prove of the causal relationship to the new requirements imposed by the phenomenon of the complex causality of environmental damage. The study focuses on the treatment conferred by the legal system and by the Spanish courts, highlighting the current context of the risk society. Therefore, the study presents the explanatory theories of the causation, stresses the concept of complex causality, as well as the existing obstacles in order to identify and verify the "environmental causality". Likewise, the existing obstacles for the identification and verification of environmental causality, such as the multiplicity of agents, the concurrence of causes and the continued damage, among others. This research also presents the existing proposals in comparative law and suggests, therefore, the incorporation of a series of
\end{abstract}

\footnotetext{
${ }^{1}$ Artículo recibido el 14 de agosto de 2019 y aprobado para su publicación el 26 de septiembre de 2019.

(*) Contratada Predoctoral del departamento de Derecho Privado de la Universidad Pablo de Olavide. Doble Máster en Abogacía y Derecho de la Contratación y Responsabilidad Civil por la Universidad Pablo de Olavide, Máster en Derecho Público por la Universidad de Sevilla. Coordinadora del Máster en Gestión de Empresas de Economía Social y Emprendimiento Colectivo. Coordinadora de sede del colectivo docente internacional innovagogía y docente de asignaturas del área de Derecho Civil (UPO). askal@upo.es
} 
theories aimed at solving the problems presented in the prove of the causation and, consequently, making civil liability an instrument effective protection and repair of environmental damage.

Keywords: Civil liability; environmental damage; causation; prove.

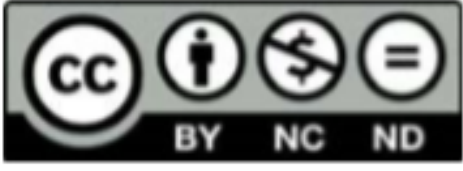

Artículo publicado bajo Licencia Creative Commons Atribución-No Comercial-Sin Derivar. (C) Universidad Católica de Córdoba

DOI http://dx.doi.org/10.22529/adc.2019(13)02 


\section{EL PROBLEMA DE LA DETERMINACIÓN DEL NEXO CAUSAL EN LA RESPONSABILIDAD CIVIL POR DAÑOS MEDIOAMBIENTALES: DE LA CERTEZA CAUSAL A LA TEORÍA DE LA CAUSALIDAD COMPLEJA}

\section{Breves comentarios iniciales}

El daño ambiental plantea un profundo debate sobre las consecuencias jurídicas normativas de la protección del medio ambiente, debido, principalmente, a la necesaria reparación de los recursos naturales para el equilibrio global. Dentro del Derecho de daños, la responsabilidad civil extracontractual representa el campo más amplio de investigación y, constantemente, se presentan nuevas propuestas para solucionar las dificultades que las nuevas relaciones jurídicas imponen al Derecho. Entre estas nuevas cuestiones está la responsabilidad civil medioambiental, porque los supuestos de daños ecológicos traen macro consecuencias que obligan al jurista a repensar la tradicional relación dual de responsabilidad civil y sus clásicos presupuestos.

Estas macro consecuencias de los daños ambientales son resultado de la sociedad del riesgo global, un concepto transcendental desarrollado por BECK en $1992^{2}$, y que defiende que los principales peligros y retos actuales de la sociedad son producidos por la propia civilización y que no se delimita socialmente ni en el espacio ni en el tiempo. El autor crea la expresión fatalismo tecnológico para expresar los inevitables riesgos que acompañan la modernidad, tratando de explicar que vivimos una edad media industrial y propone como solución más "democracia" en las decisiones relativas al medio ambiente. BECK defiende, entre otras opciones, exigir más responsabilidad de las industrias, aplicar la redistribución dela carga de la prueba, establecer una clara separación entre los creadores del peligro y los evaluadores del mismo - agencias reguladoras y fiscalización ${ }^{3}$.

En este nuevo contexto, el sistema romano clásico no abarca los supuestos ambientales, especialmente porque las reglas relativas a la responsabilidad civil fueron desarrolladas para daños entre personas, en defensa de intereses particulares ${ }^{4} \mathrm{y}$, por lo menos a principio, de carácter marcadamente patrimonial. Sin embargo, el daño ambiental rompe con el

\footnotetext{
${ }^{2}$ BECK, U. (2002), La sociedad del riesgo global. Siglo Veintiuno de España Editores, Madrid, p. 29) ${ }^{3}$ BECK (2002), p. 110.

${ }^{4}$ Álvarez LATA, N. (2014), "Responsabilidad Civil por daños al medio ambiente" en ReGLERO CAMPOS \& Busto LAGO (Coord.) Tratado de Responsabilidad Civil, tomo II, 4 ed. Aranzadi, Navarra. p. 1100
} 


\section{EL PROBLEMA DE LA DETERMINACIÓN DEL NEXO CAUSAL EN LA RESPONSABILIDAD CIVIL POR DAÑOS MEDIOAMBIENTALES: DE LA CERTEZA CAUSAL A LA TEORÍA DE LA CAUSALIDAD COMPLEJA}

esquema tradicional del daño en la esfera del patrimonio ${ }^{5}$, excluye la noción de daño resarcible - al no verse menoscabado un interés particular de un individuo ${ }^{6}$. Por esta razón genera un debate acerca de la posibilidad de imputar responsabilidad civil procedente de un daño ecológico puro ${ }^{7}$ y sobre los supuestos de aplicación de la responsabilidad civil al daño al medio ambiente.

Las cuestiones relativas al daño medioambiental son vastas y por ello nos dedicaremos solamente a una de las materias relacionadas con los nuevos retos jurídicos en este tema: el nexo de causalidad. La relación causal es un punto clave de discusión doctrinal y jurisprudencial y algunos autores ya mencionaron que el nexo "es el talón de Aquiles de la responsabilidad civil medioambiental"8, sea por la elección de una teoría de la causalidad, por el régimen de responsabilidad, por la distinción entre la causalidad material y jurídica o por la aplicación de la teoría de la "causalidad compleja, el nexo de causalidad es un tema que merece la atención, principalmente acerca de los instrumentos para flexibilizar su prueba en sede jurisdiccional. En todo caso, es el nexo causal es uno de los mayores obstáculos $^{9}$ a la hora de imputar la responsabilidad civil medioambiental, porque su comprobación fáctica es presupuesto para la imputación jurídica y, consecuentemente para la propia existencia de la responsabilidad civil.

El estudio del presente trabajo está estructurado en cuatro partes: la primera parte se ocupa del análisis de la causalidad y las principales cuestiones relacionadas con los daños ecológicos. Se aborda la naturaleza, el concepto y la necesaria distinción entre causalidad fáctica y causalidad jurídica. En la segunda parte se trata de exponer las principales dificultades que se enfrenta la prueba de la relación causal en materia ambiental, bien como

\footnotetext{
${ }^{5}$ PÉrez Fuentes, G. M. (2009), "La responsabilidad civil por daños al medio ambiente en el derecho comparado" en Prolegómenos. Derechos y Valores. V. XII, № 23 (enero-junio), p. 36.

${ }^{6}$ ÁlvareZ LATA (2014), p. 1101.

${ }^{7}$ Sobre la evolución histórica y la protección del daño ecológico puro véase: RUDA GONZÁLEZ, A. (2008), El daño ecológico puro: La responsabilidad civil por el deterioro del medio ambiente, con especial atención a la Ley 26-2007, de 23 de octubre, de responsabilidad medioambiental. Aranzadi, Navarra, págs. 31-38.

${ }^{8}$ RUDA (2008), p.292.

${ }^{9}$ ShEEHAN, L. (1991) “The EEC's Proposed Directive on Civil Liability for Damage Caused by Waste: Taking Over When Prevention Fails" en Ecology Law Quarterly, Vol. 18, No. 2, p. 418
}

\begin{tabular}{llll}
\hline \hline ANUARIO DE DERECHO CIVIL & TOMO XIII & 2019 & Página 55
\end{tabular}




\section{EL PROBLEMA DE LA DETERMINACIÓN DEL NEXO CAUSAL EN LA RESPONSABILIDAD CIVIL POR DAÑOS MEDIOAMBIENTALES: DE LA CERTEZA CAUSAL A LA TEORÍA DE LA CAUSALIDAD COMPLEJA}

ejemplos que corroboran la causalidad compleja. En la tercera parte se presenta los mecanismos que la doctrina y la jurisprudencia, tanto nacional como comparada, han encontrado para superar las barreras de la causalidad compleja expuestas en la primera parte del estudio.

Para concluir este estudio, razonamos algunas críticas al actual sistema de responsabilidad medioambiental y pretendemos presentar una propuesta de lege ferenda para tratar el tema. En definitiva, todos los aspectos señalados constituyen objetivo del trabajo, y a través de ellos pretendemos ofrecer nuevas respuestas a los problemas de la causalidad en el régimen de responsabilidad civil por daños ambientales.

\section{La causalidad: nociones y principales cuestiones}

El nexo de causalidad es la relación de causa y efecto entre el comportamiento del agente y el daño ${ }^{10}$, es el enlace entre la acción/omisión y el daño producido. Probar el nexo causal es una actividad que trata de demostrar la existencia de un vínculo entre una determinada conducta y un daño ${ }^{11}$. En el marco del Derecho de Daños, es el elemento que ha originado más discusión ${ }^{12}$, puesto que la relación causal material tiene un factor empírico, factor este que no deben confundirse con el factor técnico de imputación objetiva de la causalidad.

En líneas generales, la concatenación de acontecimientos ${ }^{13}$ - sean activos u omisivos generan siempre una reacción y si esta reacción deriva un daño habrá la obligación de indemnizar. No obstante, hay innumerables implicaciones en esta explicación tan sencilla de la responsabilidad civil y la más dificultosa de ella resulta justamente en el hilo de

\footnotetext{
${ }^{10}$ DE ANGEL YÁGÜEZ, R. (2008) "Elementos o presupuestos de la responsabilidad civil (III) la relación de causalidad" en SIERRA GIL DE LA CUESTA, I.(COORD.) Tratado de la responsabilidad civil. Tomo I, Editorial Bosch, Barcelona, p. 413.

${ }^{11}$ De Miguel Perales, C. (1994) La responsabilidad civil por daños al medio ambiente. Civitas, Madrid, p. 143

${ }^{12}$ YzQuiERdo TolsadA, M. (2017), Responsabilidad Civil Extracontractual. Parte general. 3 ed. Dykison, Madrid, p. 206

${ }^{13}$ Yanguas Montero, G. (2006), El daño no patrimonial en el derecho del medio ambiente. Editorial Aranzadi, Navarra, p.154.
} 


\section{EL PROBLEMA DE LA DETERMINACIÓN DEL NEXO CAUSAL EN LA RESPONSABILIDAD CIVIL POR DAÑOS MEDIOAMBIENTALES: DE LA CERTEZA CAUSAL A LA TEORÍA DE LA CAUSALIDAD COMPLEJA}

interrelación ${ }^{14}$ entre los acontecimientos y la relevancia de ellos en dicho daño para imputar responsabilidad civil.

En España se puede encontrar innumerables trabajos desde hace cincuenta años ${ }^{15}$ sobre el nexo causal en el ámbito civil y sus derivadas teorías para explicar la relación de causalidad, pero, en definitiva, todas son teoría para explicar la relación de causa y efecto entre el acontecimiento y el daño. Para tratar todas las teorías que se ha desarrollado para explicar la causa necesitaríamos un trabajo específico sobre el tema, por ello, en este trabajo, trataremos apenas de exponer sobre la más conocida y utilizada, la teoría de la condicio $^{16}$ sine qua non, según la cual, para que un agente tenga el deber de reparar, su conducta debe ser tan relevante a punto de que, faltado la conducta, el daño no se hubiera producido. En otras palabras, es causa del daño aquella que, si es suprimida en abstracto (in mente), entonces el daño no se habría producido en las condiciones, tiempo y lugar en que se produjo.

La "fórmula" condicio sine qua no llevada al extremo nos lleva a la equivalencia de las condiciones, determinado que, si varias condiciones concurren al mismo resultado, todas tendrían el mismo valor y la misma relevancia ${ }^{17}$.En síntesis, la teoría desarrollada en los tribunales alemanes por el magistrado Von Buri, explica que debe ser considerada causa de un determinado fenómeno la totalidad de fuerzas que, de cualquier manera, participaron para la producción de este, y esto se debe a que la existencia de tal fenómeno depende de cada una de estas fuerzas y la supresión mental de una de ellas tendrían el poder de

\footnotetext{
${ }^{14}$ DE ANGEL YÁGÜEZ (2008), p. 414.

15 Por todos: De Cossio, A. (1966), "La causalidad en la responsabilidad civil: estudio del Derecho Español” en Anuario de Derecho Civil, Vol. 19, no 3, págs. 527-554.

16 Aquí hacemos uso de la palabra en latín condicio y no conditio, por concordar vehementemente con el profesor PANTALEÓN al aclarar que la condicio significa condición en cuanto que conditio significa fundación/creación. PANTALEÓn PRIETO, F. (1990), “Causalidad e imputación: criterios de imputación”, en Centenario del Código Civil (1889-1989), Tomo II, Centro de estudios Ramon Areces, Madrid, p. 1561.

${ }^{17}$ RoxIN, C. (2002), Funcionalismo e imputação objetiva no direito penal. 3.ed. Renovar, Rio de Janeiro, pp. 122-123.DíEZ-PICAZO, L. (2011), Fundamentos del derecho civil patrimonial, Vol V: La responsabilidad civil extracontractual. Aranzadi, Navarra, p.360.
} 


\section{EL PROBLEMA DE LA DETERMINACIÓN DEL NEXO CAUSAL EN LA RESPONSABILIDAD CIVIL POR DAÑOS MEDIOAMBIENTALES: DE LA CERTEZA CAUSAL A LA TEORÍA DE LA CAUSALIDAD COMPLEJA}

suspender el propio fenómeno ${ }^{18}$.

De este modo, para determinar la relación de causalidad, se hace el tradicional test de la teoría de la equivalencia de las condiciones, conocido en la doctrina del Common Law como "but for test" ". No obstante, aplicar la teoría de la condicio sine qua non en toda su extensión, supondría que todos los factores causales presentes deben tenerse en cuenta y es para evitar esto último por lo que surge la teoría de la imputación objetiva; para elegir entre las causas presentes aquella que tienen relevancia jurídica, como tendremos ocasión de examinar (vid 1.2).

La condicio sine qua no desde el punto de vista fáctico, es la más aceptada entre la doctrina y jurisprudencia, considerando que es una pura cuestión de hecho, los PETL $^{20}$ y el $\mathrm{DCFR}^{21}$ establecen la condicio sine qua non como criterio primero para la cuestión de la causalidad fáctica. Aunque con modelos muy diferentes ${ }^{22}$, ya que el DCFR no hace la necesaria distinción entre causalidad de hecho y causalidad jurídica y los PETL empieza por la mencionada teoría, pero en seguida trae las previsiones de imputación objetiva.

La principal crítica a la condicio sine qua non es más que conocida, se trata de la regressus ad infinitum del nexo causal ${ }^{23}$, ya que una causa es resultado de otras causas, principalmente si suceden fenómenos de la naturaleza y así generaría una infinitud de causas que no responden a tarea de supresión mental que sostiene la teoría.

\footnotetext{
${ }^{18}$ YZQUIERDO (2017), p. 209.

${ }^{19}$ Fleming, J. (1998), The law of torts. The law book company, 9a. ed Sydney, p.219. MULLIS A. Y OliPHANT K. (1993), Causation. enTorts. Macmillan Professional Masters. Palgrave, London, págs.7988. LunA YeRGA, A. (2004), La prueba de la responsabilidad civil médico-sanitaria. Civitas, Madrid, p. 362 ${ }^{20}$ Artículo 3:101: "An activity or conduct (hereafter: activity) is a cause of the victim's damage if, in the absence of the activity, the damage would not have occurred".

${ }^{21}$ Libro VI - Artículo 4:101: "A person causes legally relevant damage to another if the damage is to be regarded as a consequence of that person's conduct or the source of danger for which that person is responsible. (2) In cases of personal injury or death the injured person's predisposition with respect to the type or extent of the injury sustained is to be disregarded".

${ }^{22}$ Martín-CASALS, M. (2011), "La modernización del Derecho de la responsabilidad extracontractual" en Cuestiones actuales en materia de Responsabilidad Civil. XV Jornadas APDC, Editum, Murcia, p. 44.

${ }^{23}$ INFANTE RUíZ, F. J. (2002), La responsabilidad por daños: Nexo de causalidad y <<causas hipotéticas〉> Tirant lo blanch, Valencia, p. 142.
} 


\section{EL PROBLEMA DE LA DETERMINACIÓN DEL NEXO CAUSAL EN LA RESPONSABILIDAD CIVIL POR DAÑOS MEDIOAMBIENTALES: DE LA CERTEZA CAUSAL A LA TEORÍA DE LA CAUSALIDAD COMPLEJA}

Además, la fórmula de la teoría condicio sine qua non peca en supuestos de causalidad múltiple, sea por causalidad cumulativa o concurrente, donde un número indeterminado de autores podrían haber causado el daño, sin saberse exactamente si aisladamente considerados el daño hubiera ocurrido o no, o si suprimiendo mentalmente uno de ellos la víctima hubiera o no sufrido el daño. Piénsese en las fiestas de fin de año, donde incontables asistentes celebran con pirotecnia al mismo momento y se produce un incendio en una vivienda por la entrada de un "volador", sin que se pueda acreditar que el incendio no hubiera ocurrido suprimiendo mentalmente la acción de ninguno de ellos considerados separadamente $^{24}$. Si se imputa a todos que asistían a las fiestas callejeras, el daño podría ser imputado a personas que no lo han causado y si se considerara la teoría condicio sine qua non no habría responsabilidad por falta de nexo causal.

Incluso con las mencionadas críticas, por muchos años la teoría condicio sine qua non fue la reconocida y utilizada con único criterio de determinación del nexo causal en los ordenamientos continentales, con modulaciones ${ }^{25}$, como la previsibilidad de todo el desarrollo causal por parte del sujeto o la contraposición entre la causa próxima y la causa remota $^{26}$. Hoy la teoría dejó espacio a la interpretación de los tribunales ya la apreciación dela relación de causalidad de modo conjunto a la causalidad alternativa y la causalidad concurrente, como indica los PETL. Actualmente, el único ordenamiento que todavía utiliza la condicio sine qua non como único criterio causal es Código Civil Belga de $1804^{27}$, pero que tiene un importante proyecto de reforma que, más allá de la condición sine qua non, también prevé la causalidad concurrente y la aplicación de la teoría de la

\footnotetext{
${ }^{24}$ El caso aconteció en Las Palmas de Gran Canaria en la nochevieja del año 2019. El nuevo año comenzó con un incendio provocado por un artefacto pirotécnico que entró por el balcón de una vivienda y afectó a dos plantas de un edificio. Noticia disponible en: https://www.eldiario.es/canariasahora/sociedad/voladorincendio-vivienda-La_Minilla_0_852514833.html

${ }^{25}$ Para consultarsobreestetemavéase: HART, H \&HONORÉ, T. (1985), Causation in the Law, Oxford, Clarendon Press.

${ }^{26}$ DÍEZ-PICAZO (2011), p.362.

${ }^{27}$ Martín-CASAls, M. (COORD.) (2008), Principios de derecho europeo de la responsabilidad civil. Aranzadi, Navarra, p.79
} 


\section{EL PROBLEMA DE LA DETERMINACIÓN DEL NEXO CAUSAL EN LA RESPONSABILIDAD CIVIL POR DAÑOS MEDIOAMBIENTALES: DE LA CERTEZA CAUSAL A LA TEORÍA DE LA CAUSALIDAD COMPLEJA}

causalidad alternativa ${ }^{28}$.

Aunque fueron presentadas teorías individualizadoras como la causalidad próxima que determina como causa la más inmediata en el tiempo ${ }^{29}$, la causalidad adecuada la cual defiende que es causa el hecho más probable y verosímil para causar el daño ${ }^{30}$, o incluso la teoría de causalidad eficiente, ninguna teoría ofrece completas soluciones para los problemas fácticos del nexo causal. No hay como adoptar únicamente una teoría que demuestre una solución perfecta para resolver conflictos envolviendo la prueba del nexo de causalidad en materia de responsabilidad civil.

Así la cosas, no podría ser diferente en el ámbito medioambiental, los daños ambientales están igualmente sujetos a los presupuestos de la responsabilidad civil. En la contaminación difusa, fenómeno nada infrecuente en el ámbito de la responsabilidad medioambiental, ${ }^{31}$ la relación de causalidad se advierte aún más importante, ya que identificar la causa utilizando solamente la teoría de la condicio sine qua non podría generar la exigencia de un alto grado de prueba; del curso histórico y de unicidad que no es propia de los daños ecológicos. La inadecuación de sistema tradicional pide que se adopte un sistema atento a las peculiaridades del daño ecológico ${ }^{32}$.

\subsection{La causalidad como requisito indispensable de la responsabilidad civil}

Si la imputación de responsabilidad civil por daño ambiental ya plantea un grave problema de demonstración del mismo daño, la demostración de la relación de causalidad es aún más

\footnotetext{
${ }^{28}$ Para consultar las propuestas de nuevo Código Civil Belga véase: https://justice.belgium.be/bwcc

${ }^{29}$ Para un estudio de las teorías individualizadoras, véase YZQUIERDO (2017), p. 210.

${ }^{30}$ Elaborada por el filósofo VonKries en 1888, la doctrina defiende que es un criterio de imputación objetiva, una cuestión jurídica y no debe ser tratada como una teoría de la relación de causalidad material. Por todos, véase: PANTALEÓN (1990), pp. 1561-1592.

${ }^{31}$ CABANILLAS SÁNCHEZ, A. (2017) "Los criterios de imputación de la responsabilidad medioambiental" en Embid Irujo, J.M., MiQuel GonZÁlez, J.M. \& Morales Moreno, A.M (dir) Estudios jurídicos: Liber Amicorum en honor a Jorge Caffarena, Madrid: Colegio de Registradores de la Propiedad y Mercantiles de España, p. 186

${ }^{32}$ Vaquero Pinto, M. J. (2006), "Responsabilidad civil por daños ambientales", en: Revista de Derecho Privado, año 90, p. 48 


\section{EL PROBLEMA DE LA DETERMINACIÓN DEL NEXO CAUSAL EN LA RESPONSABILIDAD CIVIL POR DAÑOS MEDIOAMBIENTALES: DE LA CERTEZA CAUSAL A LA TEORÍA DE LA CAUSALIDAD COMPLEJA}

dificultosa para la víctima, que necesita demostrar que la conducta del demandado ha sido la generadora material del daño, que su acción u omisión fue causa efectiva y cierta del perjuicio ambiental sufrido.

La jurisprudencia ${ }^{33}$ apunta que la verificación causal - la cuestión de hecho -es indiscutiblemente necesaria y debe ser probada por el demandante. Aunque la causalidad es uno de los extremos más problemáticos en relación a los supuestos de responsabilidad civil $^{34}$, no hay razón para discutir la imprescindibilidad del nexo causal. La doctrina del Tribunal Supremo determina que siempre será requisito ineludible la exigencia de una relación de causalidad entre la conducta activa o pasiva del demandado y el resultado dañoso producido, de tal modo que la responsabilidad se desvanece cuando el nexo causal no puedo concretarse ${ }^{35}$. Por supuesto, en el ámbito medioambiental se sigue la misma doctrina, sea en supuestos de responsabilidad objetiva o subjetiva, ya que la relación causa y efecto permanece indudable para imputar responsabilidad civil.

A principio, no basta que ocurra un daño ecológico, es indispensable determinar si el resultado dañoso fue consecuencia de la conducta perpetrada por un determinado sujeto, siendo imposible atribuir responsabilidad sin que exista vínculo causal, ya que, como reiteradas veces se pronunció el Tribunal Supremo, la responsabilidad por culpa extracontractual no resulta exigible cuando no es posible establecer la relación de causalidad entre la conducta activa o pasiva y el daño ocasionado ${ }^{36}$. Sin embargo, para preservar esta característica de requisito indispensable "la causalidad debió mutar bajo múltiples formas" ${ }^{\prime 37}$,y eso se debe a la complejidad de causas y efectos que caracterizan este tipo de daño, lo que ha contribuido a la aparición del fenómeno de la "causalidad

\footnotetext{
${ }^{33}$ Por todas: STS, 1a, 6 de noviembre de 2002. "En todo caso es preciso que se pruebe la existencia del nexo causal, correspondiendo la carga de la prueba al perjudicado que ejercita la acción"

${ }^{34}$ Palao Moreno, G. (1998) La responsabilidad civil por daños al medio ambiente. Tirant lo Blanch, Valencia, p. 129.

35 En este sentido véase las Sentencias del Tribunal Supremo de 3 mayo de 1995; 18 de julio de 2006 y de 30 de mayo de 2008.

${ }^{36}$ Por todas: STS de 10 de octubre de 2002

${ }^{37}$ Prevot, J. M. (2010), "El problema de la relación de causalidad en el derecho de la responsabilidad civil" en Revista Chilena de Derecho Privado, no 15, p. 154.
}

\begin{tabular}{llll}
\hline \hline ANUARIO DE DERECHO CIVIL & TOMO XIII & 2019 & Página 61
\end{tabular}




\section{EL PROBLEMA DE LA DETERMINACIÓN DEL NEXO CAUSAL EN LA RESPONSABILIDAD CIVIL POR DAÑOS MEDIOAMBIENTALES: DE LA CERTEZA CAUSAL A LA TEORÍA DE LA CAUSALIDAD COMPLEJA}

compleja".

La causalidad compleja levanta un debate sobre la necesidad de una rigurosa comprobación de tal relación, principalmente a la hora de obtener atención jurisdiccional para los daños ecológicos y consecuentemente la debida reparación del medio ambiente. Para no obstaculizar la mencionada reparación, se discute sobre la posibilidad de, en específicos casos, flexibilizar este requisito, casi al límite de dispensarlo.

$\mathrm{Al}$ considerar las características especiales del daño ambiental ${ }^{38}$ la prueba de la relación de causalidad pasa, entonces, a ser analizada desde un juicio de probabilidad - aunque apoyado en el conocimiento científico - abandonando la causalidad cierta y absoluta, sustituyéndola por la causalidad probable. Defender la flexibilización de la prueba no significa prescindir del nexo, pues "si falta relación de causalidad no habrá lugar a responsabilidad"39.

Por último, comprobar la relación entre la conducta y el daño es un paso previo para la decisión de si la conducta es imputable al sujeto agente o no. Una vez determinada la causalidad fáctica, se trata de averiguar si el daño debe ser imputado objetivamente al que lo ha causado ${ }^{40}$, por ello, el estudio, aunque breve, de imputación objetiva ${ }^{41}$ se hace inevitable.

\subsection{La necesaria distinción entre causalidad material y causalidad jurídica} (imputación objetiva)

Pese a las críticas que se hace a la teoría condicio sine qua non y todos los problemas que generan esta teoría fáctica de la causalidad, la relación causal será un tema de la exclusiva apreciación de la Sala sentenciadora $^{42}$, ya que es la causalidad jurídica la que realmente importa a la hora de hacer un análisis legal del tema. Aunque los problemas que se

\footnotetext{
${ }^{38}$ ReYes LÓPEZ, M. J. (coord.) (2001) Derecho Ambiental Español. Tirant lo Blanch, Valencia. p. 229.

${ }^{39}$ Cordero Lobato, E. (2002) "Derecho de daños y medio ambiente". en: Ortega Alvarez, L. (coord.) Lecciones de Derecho de Medio Ambiente, Lex Nova. p. 516.

${ }^{40}$ PANTALEÓN (1990), p. 1564.

${ }^{41}$ El término no debe ser confundido con responsabilidad objetiva. Para mejor explicación véase: INFANTE RuíZ, 2002, pp. 149-160.

${ }^{42}$ STS de 13 de junio de 1988
} 


\section{EL PROBLEMA DE LA DETERMINACIÓN DEL NEXO CAUSAL EN LA RESPONSABILIDAD CIVIL POR DAÑOS MEDIOAMBIENTALES: DE LA CERTEZA CAUSAL A LA TEORÍA DE LA CAUSALIDAD COMPLEJA}

presentaran sobre la causa en la responsabilidad civil por daños al medio ambiente, en un momento posterior lo que se valora es la aptitud del agente para poder imputar el daño ocasionado, no se examina su culpabilidad ${ }^{43}$ sino su capacidad de imputación. En esencia, en los Tribunales se hace doble análisis, primero una causa fáctica y luego se trata de buscar la razón suficiente para la imputación.

Esta diferenciación está presente muy a menudo en los estudios de la doctrina jurídica continental italiana, francesa, alemana ${ }^{44}$ e también española, pero aún más en la doctrina angloamericana, distinguiendo entre la "causation in fact" y la "causation in law" última va dirigida a determinar si el hecho causador del daño tiene vinculación suficientemente como para justificar la imputación de responsabilidad ${ }^{46}$.

La conexión causal va unida a la imputabilidad del agente ${ }^{47}$ y su responsabilidad pasa, obligatoriamente por el análisis de los supuestos de imputación objetiva, no dejando la responsabilidad recaer sobre el mero resultado. De hecho, cuando la causa no es atribuida jurídicamente a persona alguna el Tribunal Supremo, reiterada veces no apreció la demanda $^{48}$, al entender que la mera relación causal no basta para originar responsabilidad, es necesario que haga evidente la imputabilidad a aquél que tiene la obligación de reparar ${ }^{49}$.

Mientras que la relación de causalidad es un paso previo que busca identificar materialmente el vínculo entre la conducta y el perjuicio ${ }^{50}$, es el factor material que ha provocado el daño, mientras que la imputación objetiva no es otra cosa que causalidad jurídica; es decir, la causa relevante desde el punto de vista jurídico. Reside en saber si el daño puede o no ser jurídicamente imputado al sujeto, por ello, algunos autores defienden

\footnotetext{
${ }^{43}$ De Miguel Perales, C. (2002), Derecho español del medio ambiente. 2ed. Civitas, Madrid, p.348

${ }^{44}$ InFANTINO, M. (2013), "Il diritto comparato della causalità aquiliana", en Rivista di dirittocivile. No. 3. Cedam, Padua, p. 575.

${ }^{45}$ LUNA YERGA (2004), p. 354.

${ }^{46}$ OLIPHANT, K. (2007), "The nature of tortious liability" en The law of tort. Lexis Nexi, Londres, p.15

${ }^{47}$ STS de 27 de octubre de 1990

${ }^{48}$ De Cuevillas MatozZI, I. (2000), La relación de causalidad en la órbita del derecho de daños. Tirant lo Blanch, Valencia, p. 101.

${ }^{49}$ STS de 22 de febrero de 1946 y STS de 25 de septiembre de 2003.

${ }^{50}$ PREVOT (2010), p. 161
} 


\section{EL PROBLEMA DE LA DETERMINACIÓN DEL NEXO CAUSAL EN LA RESPONSABILIDAD CIVIL POR DAÑOS MEDIOAMBIENTALES: DE LA CERTEZA CAUSAL A LA TEORÍA DE LA CAUSALIDAD COMPLEJA}

que el nexo causal que integra la responsabilidad civil no tiene naturaleza fáctica, sino jurídica. $^{51}$

La causalidad jurídica comporta un juicio que, más allá de la mera constatación física de la relación de causalidad, obliga a valorar con criterios extraídos del ordenamiento jurídico la posibilidad de imputar el daño causado apreciando la proximidad con la conducta realizada, el ámbito de protección de la norma infringida, y la frecuencia o normalidad del riesgo creado frente a la existencia de los riesgos generales de la vida, entre otras circunstancias.

Los criterios de imputación objetiva no tienen el propósito de demostrar la relación causal, sino más bien de establecer en que hipótesis no hay causalidad jurídica y por lo tanto el agente no debe responder por el daño. Son criterios que permiten el proceso de valoración normativa entre las causas ${ }^{52}$. De hecho, la propia teoría de la adecuación no es nada más que una manifestación de la causalidad jurídica, buscando la eliminación de los nexos causales totalmente inusuales para determinar si la causa puede o no ser imputada objetivamente al actor del daño. El estudio detallado de los criterios de imputación ${ }^{53}$ objetiva excede el objeto de estudio de este trabajo, por eso, sin entrar en su discusión, analizaremos algunos de estos criterios para elucidar mejor la cuestión.

a) La causalidad adecuada

La idea fundamental de la teoría de la causalidad adecuada desarrollada POR VON KRIES es que para imputar responsabilidad no basta que el hecho haya sido condición del daño, sino que es necesario que, con base a criterios de probabilidad, sea causa adecuada para producir el daño ${ }^{54}$. Así no cabe imputar responsabilidad al agente cuando la causa es extraordinariamente improbable. Este es el criterio más utilizado por la jurisprudencia del

\footnotetext{
${ }^{51}$ Por todos, véase De MiguEl PERALES (2002), p.347.

${ }^{52}$ DíAZ-REgAÑón GARCíA-AlCALÁ, C. (2004), "Relación de causalidad e imputación objetiva en la responsabilidad civil sanitaria" en Indret, $\mathrm{n}^{\circ} 1 / 2003$, p.5.

53 Véase De Cuevillas Matozzi, I. (2000), La relación de causalidad en la órbita del derecho de daños. Tirant lo Blanch, Valencia. SIERRA GIL DE LA CueSTA, I.(COORD.) (2008), Tratado de la responsabilidad civil. Tomo I, Editorial Bosch, Barcelona. ArCos VIEIRA, Mª A. (2005), Responsabilidad civil: nexo causal e imputación objetiva en la jurisprudencia. Aranzadi, Navarra.

${ }^{54}$ DíEZ-PICAZO (2011), p. 364.
} 


\section{EL PROBLEMA DE LA DETERMINACIÓN DEL NEXO CAUSAL EN LA RESPONSABILIDAD CIVIL POR DAÑOS MEDIOAMBIENTALES: DE LA CERTEZA CAUSAL A LA TEORÍA DE LA CAUSALIDAD COMPLEJA}

TS, aunque, según SALVAdOR CODERChy FERnÁndez CREnde el TS utiliza el criterio sin denominarlo así, ya que utiliza el término "causa eficiente" cuando en realidad está realizando un juicio de causalidad adecuada ${ }^{55}$.

b) Incremento del riesgo

Un evento dañoso no puede ser imputado objetivamente a la conducta negligente que lo ha causado cuando esta conducta no ha sobrepasado los límites del riesgo permitido. Es decir, si el sujeto agente no ha incrementado el riesgo de que se produzca el evento dañoso en cuestión este hecho no será objetivamente imputado ${ }^{56}$. En este sentido decidió el Tribunal Supremo en la Sentencia de 27 de diciembre de 2002. La actora reclamó la indemnización de los daños y perjuicios sufridos como consecuencia de la inhalación de monóxido de carbono que se había acumulado en el apartamento que ocupaba debido a la defectuosa instalación de un calentador de gas butano. La demandante fundamenta su petición en la omisión de una inspección reglamentaria que debería haber sido practicada a lo largo de 4 años. Por otro lado, la empresa demuestra que, aunque hubiera practicado la inspección no habría podido comprobar la grave deficiencia y las inadecuadas condiciones del aparato. El TS decide en base al criterio del incremento del riesgo que no se puede imputar objetivamente responsabilidad a la empresa instaladora.

c) Fin de protección de la norma

Respecto al criterio de fin de protección de la norma ${ }^{57}$ no pueden sr objetivamente imputado al evento dañoso que se sitúen fuera del ámbito de la finalidad de la norma sobre la que pretende fundamentar la responsabilidad civil ${ }^{58}$. Así no decide el Tribunal Supremo en la Sentencia de 17 de marzo de 1981, "no basta la causalidad adecuada, sino que hay que determinar en qué y por qué se ha infringido la norma por la conducta del agente, pues sólo serán anti juridicas aquellas condiciones que concurren a un resultado que infrinjan la

\footnotetext{
${ }^{55}$ SAlvador CODERCh, P. y Fernández CREnde, A. (2006), “Causalidad y responsabilidad (3 $3^{\mathrm{a}}$ edición)”, InDret 1/2006, p.8

${ }^{56}$ PANTALEÓN (1990), p.1577

${ }^{57}$ Schutzzweck der Haftungsbegründende Norm

${ }^{58}$ PANTALEÓN (1990), p.1580
} 


\section{EL PROBLEMA DE LA DETERMINACIÓN DEL NEXO CAUSAL EN LA RESPONSABILIDAD CIVIL POR DAÑOS MEDIOAMBIENTALES: DE LA CERTEZA CAUSAL A LA TEORÍA DE LA CAUSALIDAD COMPLEJA}

finalidad protectora de la norma". No obstante, este criterio también es importante a la hora de imputar la responsabilidad civil, como ocurrió en la Sentencia del Superior Tribunal de Justicia de Brasil ${ }^{59}$.

d) Riesgo general de la vida

En la causalidad jurídica también encontramos el criterio de riesgo general de la vida, que certifica que no hay causalidad jurídica cuando el daño sufrido es resultado del riesgo que la víctima habría estado expuesta, aunque la acción u omisión no hubiera ocurrido. Se niega la imputación de aquellos daños que sean la conclusión de un riesgo habitualmente ligados a la existencia del daño, los daños provocados por el propio desenvolvimiento de la vida social.

Es el riesgo general de la vida (STS de 5 de enero de 2006, 21 de octubre de 2005, 11 de noviembre de 2005), los pequeños riesgos que la vida obliga a soportar (STS de 2 de marzo de 2006), o los riesgos no cualificados, pues riesgos hay en todas las actividades de la vida (Sentencia de 17 de junio de 2003 y 31 de octubre de 2006) ${ }^{60}$ son riesgos que todos estaríamos expuestos, luego no cabe hablar de imputación de responsabilidad civil.

Así como todos los criterios de imputación objetiva, el análisis del riesgo general de la vida es previo al análisis a la cuestión de la imputación subjetiva, es decir, al análisis del grado, objetiva o subjetiva, ya que si no hay causalidad no cabe hablar de responsabilidad tampoco de responsabilidad por riesgo u objetivada ${ }^{61}$. Si no hay causalidad, no hay responsabilidad

\footnotetext{
${ }^{59}$ Un ejemplo de aplicación del criterio del fin de protección de la norma fue resuelto por el Superior Tribunal de Justicia de Brasil, al afirmar que, en regla se exige la comprobación del nexo causal, sin embargo, cuando la responsabilidad es impuesta previamente por la ley no habría necesidad de probarlo. El caso versaba sobre un terreno en zona de preservación ambiental donde la ley impedía deforestar y que aun así tenía alguna área deforestada. El tribunal brasileño imputó al actual propietario la responsabilidad por los daños de la deforestación y los costes de reforestar, aunque no queda demostrado la autoría. Aunque de la lectura de la sentencia parezca que se prescinde del nexo causal, en realidad no trata de responsabilidad sin nexo causal y sí de imputación objetiva. Es un claro ejemplo de la aplicación del criterio del fin de protección de la norma. La obligación de reparar el daño es consecuencia jurídica de una norma, y la comprobación del nexo causal se hace a partir de la finalidad de la norma que determina tal consecuencia. Así las cosas, se entiende que la preservación del medio ambiente es el fin de protección de la norma y si esta norma determina que esta área no podrá ser desforestada este es un elemento jurídico y no fáctico.
}

${ }^{60}$ SAP Vizcaya, Sección 5a , de 28 de junio de 2011.

${ }^{61}$ STS de 05 de enero de 2006. 


\section{EL PROBLEMA DE LA DETERMINACIÓN DEL NEXO CAUSAL EN LA RESPONSABILIDAD CIVIL POR DAÑOS MEDIOAMBIENTALES: DE LA CERTEZA CAUSAL A LA TEORÍA DE LA CAUSALIDAD COMPLEJA}

civil, pero si hay causalidad material, pero no hay imputación objetiva, tampoco habrá responsabilidad.

Los demás criterios de imputación objetiva (prohibición de regreso, asunción del riesgo, provocación $)^{62}$, al igual que los mencionados antes, son aplicados de manera posterior a la causalidad fáctica, lo que no debe ser diferente para las demandas ambientales, ya que los problemas de la prueba del nexo se centran, básicamente, en la causalidad material, que todavía utiliza la teoría de la equivalencia de las condiciones, dicho esto, en las líneas que siguen este trabajo se refierea la causalidad fáctica por entender que los criterios de causalidad jurídica están delimitados por la doctrina y aplicados por la jurisprudencia.

2. Dificultades probatorias en materia de responsabilidad civil medioambiental: El problema de la "causalidad compleja"

La causalidad compleja es un término utilizado en la doctrina desde los años noventa para ejemplificar los desafíos que supone poner a prueba el nexo de causalidad en relación con una serie de cuestiones controvertidas como las causas concurrentes, simultaneas o sucesivas $^{63}$ en materia ambiental. Esta causalidad compleja está relacionada con diversos factores, intrínsecos o no al hecho dañoso y presenta diversos matices, entre los que cabe destacar la falta de linealidad temporal en el curso causal y la lejanía temporal entre el hecho y el daño, así como la falta de una unicidad clara entre la conducta del sujeto agente y el resultado. A modo de ejemplo, puede considerarse la cuestión de determinar de dónde partió efectivamente la emisión que provocó la contaminación de un bosque diez años después de haberse producido la primera emisión, considerando que el bosque se encuentra cerca de una zona industrial, en la que el número de empresas que desarrollan la misma actividad es elevado. En casos como este, surgen importantes problemas en materia de

\footnotetext{
62 Para un estudio de la materia véase: PANTALEÓn PRIETO, F. (1990), "Causalidad e imputación: criterios de imputación”, en Centenario del Código Civil (1889-1989), Tomo II, Centro de estudios Ramón Areces, Madrid, págs. 1561-1592. GóMEZ BENÍTEZ, J.M. (1998), Causalidad, imputación y calificación por el resultado, Ministerio de Justicia, Secretaria General Técnica, Centro de Publicaciones, Madrid.

${ }^{63}$ Benjamin, A. H.V. (1998), "Responsabilidade Civil pelo Dano Ambiental" en Revista de Direito Ambiental. n. 9/5, jan-mar, São Paulo, p. 127
} 


\section{EL PROBLEMA DE LA DETERMINACIÓN DEL NEXO CAUSAL EN LA RESPONSABILIDAD CIVIL POR DAÑOS MEDIOAMBIENTALES: DE LA CERTEZA CAUSAL A LA TEORÍA DE LA CAUSALIDAD COMPLEJA}

responsabilidad medioambiental al presentarse en un mismo fenómeno una serie de cuestiones ligadas a la "causalidad compleja".

Los daños por una exposición masificada surgen como efecto directo de la sociedad industrial, donde la concurrencia de diversos agentes y multitud de causas contribuyen a la producción de unos daños difusos, ${ }^{64}$ como los ecológicos, que hasta hace bien poco escapaban a las legislaciones de los diversos países. La causalidad de los daños ambientales es compleja porque la complejidad es inherente al propio ambiente ecológico ${ }^{65}$ y de ello derivan incertezas científicas que conducirán a un gran obstáculo a la prueba de la relación causal.

En la responsabilidad medioambiental se debe sustituir la causalidad linear por una causalidad circular, donde tanto la causa precede al efecto como genera también la causa, existiendo entre ambos una relación de "retroalimentación" 66 . Esta retroalimentación, se nota de modo más evidente en la cuestión del calentamiento global, originado por el efecto invernadero y por unos cambios climáticos tan severos que desencadenan problemas de gran complejidad y de difícil resolución con la causalidad linear.

Sin embargo, por muy eficiente que llegue a ser el sistema legal, no es posible que esté a la par que la evolución tecnológica. Es más, ni siquiera el avance tecnológico es capaz de acompañar siempre las condiciones elementales y evolutivas de la naturaleza. Por ello, resulta tan elocuente como contundente la frase pronunciada por CAFFERATTA en una ponencia presentada México hace ya una década: "si existe certeza no estamos ante un caso verdaderamente ambiental" ${ }^{\prime \prime}$.

Un primer paso para superar los problemas presentados con la causalidad compleja lo

\footnotetext{
${ }^{64}$ Morato Leite, J.R \&ARaujo Ayala, P. DE (2011), Dano ambiental: do individual ao extrapatrimonial. Teoria e prática. 3. ed. Revista dos Tribunais, São Paulo, p. 176

${ }^{65}$ PINHO, M. J. S. (2013), "Educação ambiental, cultura corporal e práxis pedagógica escolar: histórias e memórias de uma comunidade rural da Bahia" enRepositorio Faculdade de Educação, Universidade Federal da Bahia, Salvador, p. 93

${ }^{66}$ Goldenberg, I. \&CAFFERATtA, N. (2001) Daño ambiental: problemática de su determinación causal. Abeledo-Perrot, Buenos Aires, p 50.

${ }^{67}$ CAfFeratta, N. A. (2008), "Prueba y nexo de causalidad en el daño ambiental" en: Memorias del $6^{\circ}$ Encuentro Internacional de Derecho Ambiental. Foro Consultivo Científico y Tecnológico, México, p. 66.
} 


\section{EL PROBLEMA DE LA DETERMINACIÓN DEL NEXO CAUSAL EN LA RESPONSABILIDAD CIVIL POR DAÑOS MEDIOAMBIENTALES: DE LA CERTEZA CAUSAL A LA TEORÍA DE LA CAUSALIDAD COMPLEJA}

constituye la Directiva 2004/35/CE sobre responsabilidad medioambiental ${ }^{68}$, incorporada al Derecho español mediante Ley 26/2007, de 23 de octubre, de Responsabilidad Medioambiental, en la que establece la presunción del nexo causal ante las actividades de agentes especialmente contaminantes (los indicados en el Anexo III de la ley)como tendremos oportunidad de analizar (vid.3.3)

Si bien no todos los daños medioambientales presentan dificultades probatorias del nexo causal, debemos destacar los supuestos que generan una mayor dificultad en el ámbito de los "daños ecológicos", con independencia de que también puedan presentarse ante otras clases de daños.

\subsection{Multiplicidad de causas y/o actores}

El primer y más común de los problemas presentes en la materia de la "causalidad compleja" es el atinente a la "multiplicidad de factores", ya sea por la presencia ante un mismo evento dañoso de varios sujetos agentes, ya sea por la existencia de causas múltiples del daño. La multiplicidad de factores es una constante en numerosos casos de daños ecológicos, hasta el punto de que en no pocas ocasiones, bajo los esquemas tradicionales de la responsabilidad civil, los resultados han sido la falta de imputabilidad de la responsabilidad civil.

Cuando el daño es resultado de la conducta de dos o más agentes, como por ejemplo cuando varias industrias vierten residuos sobre aguas, es imposible determinar cuál es la causa única o si todas las conductas aisladas serían capaces de provocar el daño. Aquí se puede dar dos casos, uno en que las actividades aisladas no son capaces de generar daño por si sola pero cuando se une a otras actividades o circunstancias si tienen efecto dañoso, o puede ser que el resultado sería el mismo, aunque solo un único agente hubiera cometido el ilícito $^{69}$.

\footnotetext{
${ }^{68}$ Directiva 2004/35/CE del Parlamento Europeo y del Consejo, de 21 de abril de 2004, sobre responsabilidad medioambiental en relación con la prevención y reparación de daños medioambientales.

${ }^{69}$ Más ampliamente, Martín-CASAlS, M. Y SolÉFEliU, J. (2004), "Multiple tortfeasors under Spanish Law” en ROGERS (ed). Unification of tort law: multiple tort feasors. Kluwer Law Int, The Hague, págs. 189-
} 


\section{EL PROBLEMA DE LA DETERMINACIÓN DEL NEXO CAUSAL EN LA RESPONSABILIDAD CIVIL POR DAÑOS MEDIOAMBIENTALES: DE LA CERTEZA CAUSAL A LA TEORÍA DE LA CAUSALIDAD COMPLEJA}

En el primer supuesto - lo que ocurre en grandes centros industriales, donde hay una gran cantidad de empresas que desarrollan la misma actividad y que estas son potencialmente lesivas al medio ambiente -no se puede establecer con exactitud ya que no es posible aislar la contribución de cada agente a la producción del daño. Este fenómeno se conoce como "causalidad complementaria", lo cual indica que existe una contribución conjunta de varios sujetos a la producción del daño, con o sin interacción entre ellos ${ }^{70}$, y que conjuntamente producen el daño. Es frecuente la acumulación de causas que aisladas no habrían producido el daño pero que al sumarse (complementarse) con otras produce un resultado dañoso.

En el segundo supuesto, se habla de "causalidad concurrente", es decir, varias causas producirían el daño por sí solas, pero se unen a la producción del resultado final. En ocasiones también se habla de "causalidad doble". Sin embargo, esta situación no siempre resultad relevante para la imputación de responsabilidad, como aconteció en el caso del río Besós, en el que la Audiencia Provincial de Barcelona consideró que "si bien la riera también era contaminada por otros vertidos, que la han convertido en una «cloaca», el solo vertido de la empresa del acusado ya era suficiente para contaminar la riera e impedir la vida propia de la misma"71.No obstante, en otro grupo de casos, la presencia de una multiplicidad de agentes en el marco de la causalidad doble culminó con la absolución de los demandados. En este sentido, la Sentencia del Tribunal Supremo de 19 de junio de $1980^{72}$, al considerar que no había quedado demostrado que la contaminación de las instalaciones de mejillones de la demandante era exclusivamente derivada de los vertidos del Buque del demandado ${ }^{73}$.

La causalidad doble es muy común en supuestos de contaminaciones fluviales causadas por vertidos de explotaciones industriales, donde cada vertido puede provocar por sí solo la muerte de peces, pero que se potencializa por la multiplicidad de hechos y de agentes. La

213. ElLIOTT, D. (1988), "Torts with multiple causes under U.S Law" en FENYVES Y WEYERS, MultikausaleSchaden in modernenHaftungsrechten. a.M Metzner, Frankfurt, págs. 9-32.

${ }^{70}$ INFANTE RUÍZ (2002), p.23.

${ }^{71}$ SAP Barcelona, Sección $3^{\text {a }}$ de 23 de enero de 2002

${ }^{72}$ STS de 19 de junio de 1980

${ }^{73}$ RUDA (2008), p. 352. 


\section{EL PROBLEMA DE LA DETERMINACIÓN DEL NEXO CAUSAL EN LA RESPONSABILIDAD CIVIL POR DAÑOS MEDIOAMBIENTALES: DE LA CERTEZA CAUSAL A LA TEORÍA DE LA CAUSALIDAD COMPLEJA}

teoría clásica del nexo causal no es suficiente para establecer la relación en estos casos $^{74}$, porque por el simple hecho de suprimir mentalmente la acción u omisión, ningún autor respondería. Por esta razón, cuando nos encontremos ante una multiplicidad de sujetos agentes, es esencial aplicar la regla de la solidaridad (impropia) para atribuir responsabilidad a todos los agentes contaminantes en el marco de la causalidad alternativa, como tendremos la oportunidad de analizar más adelante.

\subsection{Distancia entre la acción y el efecto}

En los daños ambientales es posible que exista una disociación entre el lugar donde se verifica las consecuencias del daño y el lugar donde efectivamente se genera el daño. La distancia física implica la separación entre la conducta y el resultado, como el clásico ejemplo de la lluvia ácida, donde el efecto puede producirse a miles de kilómetros de su origen. La diferencia entre el lugar donde se cometió la acción/omisión y sus resultados, dificulta considerablemente el establecimiento de la relación de causalidad.

La ubicación en sí no es un problema de causalidad, pero la comprobación del vínculo en situaciones de contaminación que tiene su fuente en una zona sometida a la jurisdicción de un país y los efectos son percibidos e identificados en otro país ${ }^{75}$ pueden generar una gran barrera probatoria. La larga distancia física generalmente imposibilita la distinción entre las contribuciones individuales y/o colectivas en cada Estado y exige más que reglas de ubicuidad $^{76}$, un esfuerzo de la víctima para demostrar el vínculo causal ${ }^{77}$.

74 El Tribunal Supremo, en la Sentencia de 19 de junio de 1980 , desestimó la reclamación por daños por
contaminación de un buque por considerar que el demandante no había probado que la contaminación fue
exclusivamente derivada de los vertidos del demandado. Si bien es cierto que otras instalaciones también
vertieron, este criterio supone que si "todos hacen lo mismo" no hay responsabilidad y se aplique la
exceptioplurium. RUDA (2008), p.353
75 La contaminación transfronteriza alza muchas cuestiones, véase por todos: FACH GómEZ, K. (2002), La
contaminación transfronteriza en derecho internacional privado. Editorial Bosch, Barcelona.
76 Reglamento Roma II introdujo un criterio lex loci delicti commissi, de acuerdo con el cual la ley aplicable
es la del lugar en el que ocurrió el hecho generador del daño, con independencia del lugar en el que las
consecuencias de dicho acto se dieran.
77 Para las reglas procesales del supuesto véase: MosCOSO RESTOVIC, P.M. (2010), "Competencia judicial
civil internacional por daño ambiental: determinación del hecho dañoso y su extensión. El caso europeo", en
Foro, Nueva época, no 11-12, págs. 193-229. ADC, TOMO LXIV, 2011, FASC. I ANUARIO DE DERECHO CIVIL

TOMO XIII

2019

Página 71 


\section{EL PROBLEMA DE LA DETERMINACIÓN DEL NEXO CAUSAL EN LA RESPONSABILIDAD CIVIL POR DAÑOS MEDIOAMBIENTALES: DE LA CERTEZA CAUSAL A LA TEORÍA DE LA CAUSALIDAD COMPLEJA}

En la doctrina del Common Law, este examen se hace aún más difícil en virtud de la teoría "remotenessofdamage" la cual exige, además de la prueba del nexo causal, establecer que el daño sufrido no es demasiado remoto, es decir, que hay una cierta previsibilidad que el daño pueda ocurrir. Según los autores, la remotidad está diseñada como un límite adicional en una causa de acción para garantizar que la responsabilidad de pagar los daños y perjuicios se coloque de manera justa sobre el acusado ${ }^{78}$.

Según el inventario Nacional de emisiones de Contaminantes atmosféricos, publicado en enero de 2019, las emisiones de amoniaco (NH3) en España superan el límite máximo durante todo el periodo de cumplimiento (2010-2017) del Protocolo de Gotemburgo del Convenio de Ginebra contra la Contaminación Atmosférica Transfronteriza a Larga Distancia (CLRTAP), con un exceso de emisiones de $+34 \%$ de media sobre el techo establecido $^{79}$.

El amoníaco es emitido a la atmósfera principalmente por el sector agrícola y estas emisiones regresan a la superficie, bien en forma de depósito seco o bien son arrastradas por la lluvia. Constituye uno de los contaminantes ácidos más importantes, dado que su depósito puede causar grandes daños a los ecosistemas naturales sensibles a la acidificación. Los gases acidificantes pueden permanecer en el aire durante varios días y ser dispersados a largas distancias, provocando efectos en zonas muy alejadas de su fuente de emisión.

\subsection{Daños continuados}

Los daños continuados - daños de tracto sucesivos - son la manifestación de unos perjuicios derivados de una única conducta que se prolonga en el tiempo. Se caracteriza por ser crónico y persistente. Los daños continuados resultan de un foco de contaminación cuyo resultado perdura a lo largo del tiempo o que después de un determinado transcurso de tiempo y sin nueva conducta activa del autor del daño, son diagnosticados. Por esta razón,

\footnotetext{
${ }^{78}$ HARPwOOD. V. (2003), Modern Tort Law. Cavendish, London, $5^{\mathrm{a}}$ ed, p. 151

${ }^{79}$ Informe del Ministerio para la Transición Ecológica: https://www.miteco.gob.es/es/calidad-y-evaluacionambiental/temas/sistema-espanol-de-inventario-sei-/Inventario-Contaminantes.aspx
}

\begin{tabular}{llll}
\hline \hline ANUARIO DE DERECHO CIVIL & TOMO XIII & 2019 & Página 72
\end{tabular}




\section{EL PROBLEMA DE LA DETERMINACIÓN DEL NEXO CAUSAL EN LA RESPONSABILIDAD CIVIL POR DAÑOS MEDIOAMBIENTALES: DE LA CERTEZA CAUSAL A LA TEORÍA DE LA CAUSALIDAD COMPLEJA}

el Tribunal Supremo ya hizo clara distinción entre los daños inmediatos y los daños continuados, imputando responsabilidad por los daños continuados al autor de la primera conducta que desencadenó los daños posteriores ${ }^{80}$.

Los daños que continúan en el tiempo no son per se un problema de causalidad, sino que un problema de prescripción, por lo que suele plantearse cuál es el inicio del plazo de prescripción de la acción, por ello, el Tribunal Supremo tiene mantenido la doctrina que en los daños continuados el plazo prescriptivo empieza a contar desde el momento en que se produce el daño definitivo o se alcance total del resultado ${ }^{81}$.

Sin embargo, la fórmula del Tribunal Supremo solo es aplicable cuando se consigue establecer la relación causal entre la acción que originó el primer daño y los daños continuados posteriores. Esto nos remite a que los daños que continúan en el tiempo traen consigo el problema de comprobar la relación de causalidad con el acto inicial, principalmente cuando hablamos de daños ecológicos, que implican el reconocimiento de factores naturales de degradación y que se suman a los actos de terceros. En efecto, los daños continuados normalmente se suman a fuentes difusas y a la combinación de una serie de factores que dan origen a los daños posteriores, lo que hace imposible la identificación del responsable, de ahí ser tan imperioso sustituir el mecanismo clásico de responsabilidad civil y establecer sistemas alternativos ${ }^{82}$.

\footnotetext{
${ }^{80}$ STS de 05 de abril de 1988: El actor y el demandado eran propietarios de fincas colindantes que se hallaban inicialmente una debajo de la otra sin cortes o diferencias bruscas de nivel, de modo que podía transitarse fácilmente entre ellas. El demandado comenzó a explotar una industria de materiales de construcción, utilizando para ello la arcilla de su finca, que extraía mediante excavaciones, lo que rebajó considerablemente el nivel de aquélla, actividad luego continuada por «Forjados Menéndez, S. A.», codemandada, creándose entre ambos predios un talud de considerable altura, lo que dio lugar a sucesivos y continuos desprendimientos.

${ }^{81}$ STS de 20 de septiembre de 2008.

${ }^{82}$ Gomis Catalá, M. L. (1998). Responsabilidad por daños al médio ambiente. Arazandi Editorial, Pamplona, p.91.
} 


\section{EL PROBLEMA DE LA DETERMINACIÓN DEL NEXO CAUSAL EN LA RESPONSABILIDAD CIVIL POR DAÑOS MEDIOAMBIENTALES: DE LA CERTEZA CAUSAL A LA TEORÍA DE LA CAUSALIDAD COMPLEJA}

Piénsese, por ejemplo, en los supuestos de accidentes nucleares, como el accidente nuclear de Fukushima I, siguen generando daños después de más de una década, cada muerte en la "zona" del accidente puede estar o no relacionada, y demostrarlo no es una tarea sencilla.

\subsection{Daños tardios}

A diferencia de lo que acontece en la materia de los daños de tracto sucesivo, en los daños tardíos no se verifica en un primer momento la existencia del daño, no hay, por lo menos a principio, ningún perjuicio derivado de la acción u omisión de un sujeto, luego si no hay daño no hay responsabilidad. El problema es que este tipo de daño solo se manifestará después de un medio o largo período de tiempo, lo que imposibilita no solo la comprobación del nexo, sino del mismo acto o a la individualización del responsable.

En el contexto de los daños tardíos aparecen multiplicidad de sujetos agentes cuando hablamos de empresas que ya no existen cuando otra se encuentra en el mismo local, constatándose después de varios decenios la contaminación del suelo ${ }^{83}$. Se suman a la multiplicidad de causas cuando en la misma región hay varias empresas diferentes, agricultores y pecuaria, y se constatan años más tarde la contaminación de aguas. Aquí verificamos un sinfín de posibilidades que dificultan la responsabilización de un actor por falta de comprobación del nexo causal.

Los daños tardíos son ocasionados por una reactivación de los daños padecidos anteriormente, en tanto que se manifiestan o conocen con posterioridad a las lesiones anteriores ya conocidas, tras el transcurso por lo general de un lapso de tiempo más o menos largo ${ }^{84}$. Un ejemplo de daños tardíos puede encontrarse en el conocido "Caso

\footnotetext{
${ }^{83}$ A modo de ejemplo, piénsese, la fábrica de plástico AA instalada del año 1979 hasta el año 1990 en una determinada zona, presuntamente realiza vertidos en el río Guadalquivir. En el año 1990 la fábrica quiebra y el local se queda desactivado hasta el año 2010 cuando la fábrica de calzado XX adquiere la nave por subasta pública y se instala en el mismo local. En el año 2018 se verifica la contaminación del río en una zona a $100 \mathrm{~km}$ de las instalaciones. ¿Quién es el responsable por la contaminación? ¿Se podría imputar responsabilidad a XX? ¿Cómo probar el nexo causal entre la conducta de la empresa AA y la contaminación?

${ }^{84}$ Avilés GarcíA, J. (2016), Comentario a la Sentencia de 20 de octubre de 2015 (RJ 2015, 4226). Revista Cuadernos Civitas de Jurisprudencia Civil num. 101/2016. Editorial Civitas, SA, Pamplona, p. 4.
} 


\section{EL PROBLEMA DE LA DETERMINACIÓN DEL NEXO CAUSAL EN LA RESPONSABILIDAD CIVIL POR DAÑOS MEDIOAMBIENTALES: DE LA CERTEZA CAUSAL A LA TEORÍA DE LA CAUSALIDAD COMPLEJA}

Talidomida" ${ }^{95}$, donde gran parte de la complejidad del asunto radicaba en que se recorría una serie de daños en el procedimiento, donde se muestran multitud de dolencias asociadas a lesiones de espalda y columna (escoliosis), artrosis severa y debilidad y tensión muscular graves, y que AVILÉS GARCÍA apunta precisamente que fueron los daños tardíos los que la sentencia de primera instancia generalizó indebidamente al encadenarlos erróneamente con los daños continuados ${ }^{86}$.

No obstante, los daños tardíos no solo generan el problema de la certeza científica, sino que generan la falsa relación causal entre el sujeto que actualmente podría causar el daño en el momento de su aparición y él que de hecho lo causó. En el caso citado, existían varios laboratorios que distribuyeron medicamentos con el principio activo, y el tiempo transcurrido desde los hechos hasta la aparición de los daños torna prácticamente imposible acreditar qué medicamento concreto fue suministrado y consumido por las madres gestantes de los afectados, de manera que no sería posible establecer la participación precisa que ha de atribuirse en el hecho dañoso a cada uno de los laboratorios que distribuyeron productos con talidomida, ni individualizar los comportamientos ${ }^{87}$.

\subsection{Verificación técnica de la relación causa / efecto}

Probablemente una de las mayores trabas con las que la indemnización de los daños ecológicos se encuentra sea el del desarrollo de la propia ciencia, la cual cada día avanza más, pero siempre se encuentra un paso por detrás de los daños producidos por contaminación medioambiental. A menudo el examen científico de los daños ecológicos

\footnotetext{
${ }^{85}$ La talidomida empezó a comercializar como un tranquilizante sin receta, bajo el nombre comercial de "Contergan", entre cuyas indicaciones se incluye el uso para las embarazadas contra las náuseas y mareos. Poco después de su introducción en el mercado se produjo un incremento espectacular de niños nacidos con focomelia y otras alteraciones genéticas graves, como la ausencia o reducción de extremidades superiores e inferiores, malformaciones de órganos internos, alteraciones auriculares y visuales. Véase NAVARROMichel, M. (2016), "Daños causados por la Talidomida. La batalla legal que no cesa. Comentario a la STS de 20 de octubre de 2015" en Revista Bioética y Derecho no 37, Barcelona.

Salvador Coderch, P.; Goméz Liguerre, C.; Rubí Puig, A.; Ramos GonzÁlez, S. \& Terra IbáÑez, A. (2014), “Daños Tardíos" en InDret1/2014, (www.indret.com)

${ }^{86}$ AvilÉs GARCÍA (2016), p. 6.

${ }^{87}$ Fundamento $2^{\circ}$, de la Sentencia del Juzgado de Primera Instancia n ${ }^{\circ} 90$ de Madrid, de 19 de noviembre de 2013.
} 


\section{EL PROBLEMA DE LA DETERMINACIÓN DEL NEXO CAUSAL EN LA RESPONSABILIDAD CIVIL POR DAÑOS MEDIOAMBIENTALES: DE LA CERTEZA CAUSAL A LA TEORÍA DE LA CAUSALIDAD COMPLEJA}

resulta $\operatorname{arduo}^{88}$ y costoso, siendo este el principal argumento para flexibilizar la rigidez del requisito causal. Los daños ecológicos pueden surgir de distintos actos de contaminación, de distintas personas, de actos divididos en el tiempo e incluso con distancias territoriales asombrosas haciendo la tarea científica aún más delicada.

El avance científico determina que la propia prevención de los daños sea más eficaz, y cuando aun así ocurren - es notorio que las pruebas en el año 2019 son más clarificadoras que en el año 1970 - la ciencia no es capaz de definir con exactitud los procesos causales materiales, justamente porque los daños que se generan en el entorno material tienen una naturaleza especialmente compleja.

Las incertezas científicas conducen a no resolver casos en los que existe un factor de riesgo preexistente que se suma a un agente contaminador, pero no se puede determinar si los daños son causa del primero factor o de los riesgos incrementados. MARTín-CASALS presenta un caso muy clarificador de víctimas no identificadas que muy bien nos puede servir de ejemplo para ilustrar la cuestión de la "falta de certeza científica. Una fábrica se instala cerca de una gran ciudad donde se producían 20 casos de cáncer al año y lanza a la atmósfera emisiones cancerígenas. A los 5 años de su instalación el número de casos de cáncer se ha incrementado, 3 individuos diagnosticados con cáncer presentan una demanda de responsabilidad civil contra la fábrica por entender que esta es causa de su enfermedad ${ }^{89}$. La ciencia no es capaz de determinar si los sujetos padecen la enfermedad a causa de las emisiones o si, en todo caso, tendrían la enfermedad por vivir en una gran ciudad con factores independientes de la responsabilidad de alguien.

\footnotetext{
${ }^{88}$ BonORINO, P. Y LEAL, V. (2010), "La prueba de la causalidad en el daño ambiental" en Avances en ciencias de la tierra, $\mathrm{N}^{\circ} 1$, p. 42.

${ }^{89}$ MARTín-CASALS (2011), pp. 47-48.
} 


\section{EL PROBLEMA DE LA DETERMINACIÓN DEL NEXO CAUSAL EN LA RESPONSABILIDAD CIVIL POR DAÑOS MEDIOAMBIENTALES: DE LA CERTEZA CAUSAL A LA TEORÍA DE LA CAUSALIDAD COMPLEJA}

\section{Parte tercera: mecanismos de flexibilización o facilitación de la prueba de la causalidad}

La dificultad que plantea la acreditación del nexo causal en materia de daños ambiental es innegable ${ }^{90}$, por lo que flexibilizar la carga probatoria es asumir que la relación causa y efecto no tiene que ser "determinística", como una relación mecánica, sino que puede ser una causalidad probabilística, con matices procesales a la hora de encarar la obligación de probar e incluso siendo posible la aplicación de presunciones legales. Para tal finalidad, abordaremos a continuación, si quiera brevemente, algunas teorías sobre la probidad del nexo causal en los ordenamientos jurídicos que en mayor o menor medida han procedido a una cierta "flexibilización" de la prueba del nexo causal.

\subsection{La inversión de la carga de la prueba}

Sin duda, la inversión de la carga de la prueba es uno de los mayores logros procesales que las legislaciones han asumido a la hora de proteger las víctimas del daño, pues transfiere al demandado la necesidad de probar que no hay relación causal entre su conducta y el daño alegado. Para que operen este tipo de regla no es suficiente con la mera alegación, sino que es preciso un indicio de prueba de lo afirmado, de hecho, algunos autores afirman que, si la ley lo determina, él juez no está invirtiendo la carga de la prueba, está simplemente distribuyéndola de otra manera ${ }^{91}$.

Defender la inversión de la carga de la prueba del nexo causal puede basarse en la presunción, es decir, la inversión de la carga de la prueba estaría relacionada con las presunciones legales ${ }^{92}$ iuris tantum de la causalidad, en cuanto que no establece la supresión del nexo, sino que transfiere al demandado la obligación de demostrar que no hay relación de causalidad.

\footnotetext{
${ }^{90}$ CABANILlaS SÁNCHES, A. (1994) "El daño ambiental” en Revista de derecho ambiental, no 12, p. 19

${ }^{91}$ DAMIÁN MORENO, J. (2007) "Nociones generales sobre la carga de la prueba en el proceso civil” en CORTÉS DomíngueZ, V. Carga de la prueba y responsabilidad civil. Tirant lo Blanch, Valencia, p. 18.

${ }^{92}$ RogelVIDE, C. (1979), "Responsabilidad civil extracontractual, culpa objetiva o por riesgo. Falta y relación de causalidad. Inversión de la carga de la prueba" en Anuario de derecho civil, Vol. 32, n 1, p. 280.
} 


\section{EL PROBLEMA DE LA DETERMINACIÓN DEL NEXO CAUSAL EN LA RESPONSABILIDAD CIVIL POR DAÑOS MEDIOAMBIENTALES: DE LA CERTEZA CAUSAL A LA TEORÍA DE LA CAUSALIDAD COMPLEJA}

En este sentido, señala PANTALEón que, en cuanto a la relación de causalidad, podría admitirse la carga de la prueba de forma excepcional, en los casos de responsabilidad de médicos u otros profesionales para garantizar la igualdad de armas, una vez producido un daño correspondería al demandado probar que fue otra circunstancia que lo produjo. Esta idea puede extrapolarse perfectamente a las demandas de responsabilidad ambiental, por considerar el mismo carácter de "sujeto sin igualdad de armas" de las víctimas y por el carácter "impenetrable" y "opaco" de algunas actividades ${ }^{93}$.

Sin embargo, hay quien defiende que la inversión de carga de la prueba va en contra del principio constitucional de presunción de inocencia ${ }^{94}$ y por eso sería más aconsejado que el juez atenúe su rigor sin invertirla y otros que consideran la inversión inadmisible, puesto que admitir la inversión de la carga a criterio del juez sería aceptar que la jurisprudencia puede hacer interpretación contra legem ${ }^{95}$. De ahí que se afirme que la inversión de la carga de la prueba del nexo causal en España sería muy poco probable, por poner sobre el demandante la carga de probar que no causó ${ }^{96}$ el daño y por ello es preferible la presunción a la inversión. ${ }^{97}$

Si estamos de acuerdo que la presunción es preferible, tenemos que manifestar que la inversión de la carga de la prueba es el reconocimiento del desequilibrio económico que casi siempre está sometido el demandante y el desconocimiento técnico de los procesos que generan los daños ambientales y por eso, cuando el poseedor de la información técnica es el demandado, es la mejor y única forma de establecer el vínculo entre la acción y el daño. Actualmente el Tribunal Supremo solo ha reconocido la inversión de la carga en los casos

\footnotetext{
${ }^{93}$ Pantaleón Prieto, F. (1991), “Comentario al art. 1902 CC”, en Comentario del Código civil. Ministerio de Justicia, Tomo II, Centro de Publicaciones, Madrid, p. 1983.

${ }^{94}$ CABANILlas SÁNCHEZ, A. (1990) "La responsabilidad por daños ambientales según la jurisprudencia civil" en Revista de Derecho Ambiental, n 6, p. 94

${ }^{95}$ Cortés Domínguez, V. \& Moreno Catena, V. (2017), Derecho procesal civil. Parte General. 8 a ed. Tirant lo Blanch, Valencia, págs. 226.

96 Podría argumentar la prueba diabólica, ya que la prueba de la inexistencia de un hecho resultara especialmente difícil y en cambio muy fácil la comprobación de su existencia, el juez deberá tener en cuenta la circunstancia.

${ }^{97}$ RUDA (2008), p.337.
} 


\section{EL PROBLEMA DE LA DETERMINACIÓN DEL NEXO CAUSAL EN LA RESPONSABILIDAD CIVIL POR DAÑOS MEDIOAMBIENTALES: DE LA CERTEZA CAUSAL A LA TEORÍA DE LA CAUSALIDAD COMPLEJA}

de riesgos extraordinarios, daño desproporcionado y la falta de colaboración del causante del daño cuando está obligado a ello ${ }^{98}$.

Por otro lado, como regla general, el Tribunal Supremo no ha aceptado una inversión de la carga de la prueba ${ }^{99}$, conservando la doctrina de que la carga de la prueba del nexo incumbe al demandante ${ }^{100}$, quién debe presentar la relación de causalidad entre la conducta activa o pasiva del demandado y el resultado producido. Este es el entendimiento mantenido desde la Sentencia de 14 de febrero de 1994, donde el Tribunal analizó un pedido de resarcimiento de los daños y perjuicios producidos a consecuencia de un incendio en un piso por parte de la propietaria de la vivienda. Sin embargo, la demandante no logra demonstrar la relación causal entre el incendio y la acción/omisión del demandado (arrendatario del piso). El Tribunal afirma que la prueba de la relación causal no alcanza la presunción ínsita en la doctrina de la inversión de la carga de la prueba, debiendo ser el actor quien pruebe la realidad del hecho imputable al demandado del que se hace surgir la obligación de reparar el daño causado ${ }^{101}$.

\subsection{La doctrina de la "causalidad probabilística" del Derecho español}

Las primeras sentencias del Tribunal Supremo español que exigían tajantemente que la relación causal debe ser concreta y precisa, siendo "imprescindible la prueba legal de su indiscutible certeza" ${ }^{102}$, han sido superadas en tiempos más recientes por una jurisprudencia menos dogmática relativa al denominado "juicio de probabilidades"103en virtud de la cual,

\footnotetext{
${ }^{98}$ STS de 23 de julio de 2008

${ }^{99}$ STS de 22 de febrero de 2007; 23 de mayo de 2007 y 21 de mayo de 2009.

${ }^{100}$ STS de 06 de febrero de 2012: Un incendio de un remolque frigorífico mientras hacía las labores de carga y descarga en un supermercado fue objeto de análisis por parte de la Sala primera del Tribunal Supremo, que, al analizar si el incendio tuvo su origen causal en una acción u omisión imprudente del conductor , reitera que, no basta la culpa; es preciso acreditar la existencia de una relación de causalidad entre la conducta del demandado susceptible de crear el riesgo y el daño producido y que la prueba del nexo casual siempre incumbe a quien demanda.

${ }^{101}$ En este sentido las Sentencias más recientes de las Audiencias Provinciales de Granada (Sección 3), de 6 mayo de 2011; de Pontevedra (Sección 4), de 8 noviembre 2002 y la de Murcia (Sección 5) de 31 enero de 2011.

102 STS de 28 de junio de 1979.

${ }^{103}$ STS de 7 octubre de 2004.
} 


\section{EL PROBLEMA DE LA DETERMINACIÓN DEL NEXO CAUSAL EN LA RESPONSABILIDAD CIVIL POR DAÑOS MEDIOAMBIENTALES: DE LA CERTEZA CAUSAL A LA TEORÍA DE LA CAUSALIDAD COMPLEJA}

ante determinados eventos dañosos, es posible concluir que existe una probabilidad razonable para afirmar la existencia de la causalidad.

La doctrina anterior sostenía que la prueba del nexo debería ser indiscutible, y así lo determinó en caso de una reclamación de cantidades por daños en una plantación ocasionados por la alta temperatura del agua utilizada para el riego que procedía de la misma acequia a la que revertía una fábrica Azucarera.

La demanda fue desestimada en primera instancia por entender que "si bien puede deducirse la existencia de una acción u omisión negligente de parte de la demandada, al no poseer en la fábrica los elementos correctores de los residuos de las aguas, así que consta la realidad del daño (muerte de árboles del vivero), en cambio no se ha demostrado la relación causal concreta y precisa, no habiendo sido posible determinar cuál fuera la verdadera causa de dicho daño". La decisión fue objetivo de recurso y la Audiencia confirma que: "no aparece probado en autos que la temperatura de las aguas provenientes de la Azucarera haya sido la causa real, verdadera y eficiente de la pérdida de las plantas del actor". En casación, el Tribunal Supremo confirma la decisión de las instancias ya que el "resultado probatorio referente al nexo causal, no puede ser sustituido por deducciones, conjeturas o probabilidades, es imprescindible prueba legal de su indiscutible certeza".

El cambio de paradigma fue proporcionado por el "Caso aceite de Colza"104 cuando la idea de causalidad estricta se abandonó y el criterio de probabilidades empezó a ser utilizado para determinar la causalidad. La Sentencia de la Sala $2^{\text {a }}$ estableció que "en los nexos causales de cierta complejidad siempre existe la posibilidad de aumentar las exigencias de los presupuestos de formulación de una ley causal natural hasta límites que prácticamente hagan imposible superar el non liquet", de esta manera el mencionado caso, la causalidad que nunca llego a ser probada, se presumió can base en indicios ${ }^{105}$.

${ }^{104}$ Las Sentencias del Tribunal Supremo de 23 de abril de 1992 y de 26 de noviembre de 1997 resolvieron respectivamente, las responsabilidades penales y civiles derivadas del envenenamiento masivo de personas que consumieron aceite de colza desnaturalizado.

${ }^{105}$ LUNA YERGA (2004), pp. 359-360. 


\section{EL PROBLEMA DE LA DETERMINACIÓN DEL NEXO CAUSAL EN LA RESPONSABILIDAD CIVIL POR DAÑOS MEDIOAMBIENTALES: DE LA CERTEZA CAUSAL A LA TEORÍA DE LA CAUSALIDAD COMPLEJA}

En la Sentencia de la Sala $1^{\text {a }}$ de 7 octubre de 2004, el Tribunal Supremo resuelve el caso de la muerte por electrocución de un joven músico mientras actuaba en un Orquesta. En el transcurso de la demanda queda probada la Orquesta tenía instalaciones defectuosas, pero no queda demostrado que la electrocución derive de las deficiencias de las instalaciones. En la decisión, el Tribunal Supremo entiende que, aunque la carga de la prueba de la base fáctica de la relación de causalidad es del demandante y que, si bien no hay certeza absoluta de que las malas condiciones fueron la causa de la electrocución, la relación causal aparece como probable en un juicio de probabilidad cualificada.

En el ámbito medioambiental, flexibilizar la carga probatoria puede facilitar al perjudicado la tarea que le incumbe a la hora de aportar las pruebas necesarias para poder exigir la responsabilidad. Así, desde la década de los ochenta, la teoría de las probabilidades es presentada por los tribunales españoles ${ }^{106}$ como la mejor solución para determinar el nexo causal en el ámbito medioambiental. Esta tendencia ha recibido el refrendo de la doctrina especializada ${ }^{107}$,cual afirma que las incertezas no tienen que conducir a las incertezas jurídicas.

En efecto, el criterio de probabilidades también objeto de análisis por parte del Tribunal de Justicia de la Unión Europea. El artículo 4 de la Directiva sobre Responsabilidad por los daños causados por productos defectuosos (Directiva 85/374/CEE) ${ }^{108}$ fue objeto de cuestión prejudicial a partir de un caso francés ${ }^{109}$, donde se preguntó si el juez podría considerar, en el ejercicio de la facultad de apreciación, que existe relación causal a pesar de la

\footnotetext{
106 Sentencias del Tribunal Supremo, Sala $1^{\mathrm{a}}$, de 14 de julio de 1982 sobre daños causados en finca naranjera por de explosiones y emanaciones de polvo de fábrica; de 13 de junio de 1988, sobre daños por contaminación de río; de 16 de enero de 1989 sobre daños producidos por contaminación industrial.

107 Véase: Gomis CATALÁ (1998); De Miguel Perales (1994) \&CABANILlAS SÁnCHEZ (1994)

108 Artículo 4: El perjudicado deberá probar el daño, el defecto y la relación causal entre el defecto y el daño.

109 La cuestión prejudicial fue presentada en el contexto de un litigio entre las Sras. N., L. y C. W (hijas del Señor W) contra "Sanofi Pasteur" debido a los daños causados por una vacuna supuestamente defectuosa producida por dicha sociedad. El Sr. W fue vacunado contra la hepatitis B mediante una vacuna producida por Sanofi Pasteur, que se le administró en tres inyecciones en el 1999. En noviembre de 2000 se le diagnosticó esclerosis múltiple. En 2006 interpuso demanda, en la que solicitaba indemnización por los daños que habían sufrido como consecuencia de la administración de la vacuna controvertida, que según el demandante fue la causa de su enfermedad.
}

\begin{tabular}{llll}
\hline \hline ANUARIO DE DERECHO CIVIL & TOMO XIII & 2019 & Página 81
\end{tabular}




\section{EL PROBLEMA DE LA DETERMINACIÓN DEL NEXO CAUSAL EN LA RESPONSABILIDAD CIVIL POR DAÑOS MEDIOAMBIENTALES: DE LA CERTEZA CAUSAL A LA TEORÍA DE LA CAUSALIDAD COMPLEJA}

consideración de que la investigación médica no ha demostrado ni refutado la existencia de una relación entre la vacuna y la enfermedad, cuando el demandante presenta hechos que constituyen indicios sólidos, concretos y concordantes.

La respuesta del TJUE, en esencia, afirma que la Directiva "no exige al perjudicado que aporte, en todo caso, pruebas concretas e irrefutables de la existencia del defecto del producto ni de la relación de causalidad entre este último y el daño sufrido, sino que autoriza al juez, en su caso, a considerar que estos extremos han quedado demostrados basándose en un abanico de indicios cuya solidez, concreción y concordancia le permitan considerar, con un elevado grado de probabilidad, que tal conclusión corresponde a la realidad". 110

El criterio establece que el demandante no está obligado a probar la relación de causalidad común a exactitud rayana en la certeza ${ }^{111}$, lo que supone cierta apertura o asunción con relación a la complejidad y las "certezas relativas" del problema causal. De este modo, solo es necesario que el juez identifique la existencia de un grado suficiente de probabilidad ${ }^{112}$ para restar probada la relación de causalidad. En definitiva, hay la sustitución del criterio certeza por el criterio probabilidad, lo que torna la tarea de probar el nexo causal menos ardua.

Como bien es sabido, es doctrina jurisprudencial totalmente asentada la que establece que la carga de la prueba sobre los aspectos fácticos de la relación de causalidad corresponde al demandante. Pero al mismo tiempo también es jurisprudencia consolidada la referente a la doctrina de la facilidad probatoria, de acuerdo con la cual no es necesario exigir al demandante que presente pruebas absolutas corroboradas científicamente, pues lo contrario sería desvirtuar la situación de desigualdad de las víctimas de desastres ambientales.

\footnotetext{
${ }^{110}$ Sentencia TJUE (Sala $2^{\mathrm{a}}$ ) de 21 de junio de 2017. Caso N. W y Otros contra Sanofi Pasteur MSD SNC y Otros. Sentencia de. TJCE 2017\147

${ }^{111}$ GOMIS CATALÁ (1998), p. 165.

${ }^{112}$ De ANGEL YÁGÜEZ, R. (1995), Algunas previsiones sobre el futuro de la responsabilidad civil (con especial atención a la reparación del daño) Editorial Civitas, Madrid, p. 77.
} 


\section{EL PROBLEMA DE LA DETERMINACIÓN DEL NEXO CAUSAL EN LA RESPONSABILIDAD CIVIL POR DAÑOS MEDIOAMBIENTALES: DE LA CERTEZA CAUSAL A LA TEORÍA DE LA CAUSALIDAD COMPLEJA}

Es reconocible que, en algunas sentencias, pese a exigir una prueba incuestionable, se hace posible la prueba pericial y se permite la prueba de la relación de causalidad, como aconteció en el célebre "caso del Río Tajo", en el que una piscifactoría pudo probar el nexo causal entre el aumento de la temperatura del río Tajo provocada por la central nuclear "José Cabrera" y la muerte de sus truchas, lo cual consiguió probar de manera cierta y precisa, pero mediante cierta facilidad probatoria ${ }^{113}$.

No obstante, este ejemplo también nos demuestra que, por otra parte, exigir la absoluta certeza probatoria, conlleva la imposibilidad de probar el nexo causal cuando el estado de la ciencia, a través de los exámenes periciales, no puede demostrar todos los procesos físicos o químicos que llevan al resultado, con la grave consecuencia de dejar sin reparación la mayoría de los daños ecológicos. Con razón, son cada vez más frecuentes las sentencias que mediante juicio de probabilidad consideran probados los hechos alegados por la víctima ${ }^{114}$.

\subsection{El sistema de presunción legal de la causalidad del Derecho alemán}

La ley alemana de responsabilidad medioambiental ${ }^{115}$ establece un sistema de presunciones sobre la inversión de la carga de la prueba. Mediante presunciones iuris tantum se transfiere la obligación al demandado de probar que respetó la legislación, cumplió los deberes específicos de su actividad y que ésta no tenía anomalías significativas.

No obstante, el demandado puede excepcionar la presunción si demuestra que la instalación ha sido utilizada de forma adecuada y estándar, que ha cumplido con todos los deberes de funcionamiento, tanto administrativos como jurídicos. Es decir, el demandado que demuestre que ha desarrollado todas las medidas necesarias para prevenir el impacto

\footnotetext{
113 STS de 16 de enero de 2002

${ }^{114}$ ARCOS VIEIRA, Ma. A. (2005), Responsabilidad civil: nexo causal e imputación objetiva en la jurisprudencia. Aranzadi, Navarra, p. 147.

115 "Umwelthaftungsgesetzvom 10. Dezember 1990 (BGBl. I S. 2634), das zuletztdurchArtikel 6 des Gesetzesvom 17. Juli 2017 (BGBl. I S. 2421) geändertwordenist". La ley puede encontrarse traducida en CAÑIZARes LASO, A. Y Rodríguez TAPIA, J.M. (1994), La nueva regulación alemana en materia de responsabilidad por daños causados al medio ambiente" en Anuario de Derecho Civil, Tomo XLVII Fascículo I. Publicado por Ministerio de Justicia, Madrid, págs. 209 y ss.
}

\begin{tabular}{llll}
\hline \hline ANUARIO DE DERECHO CIVIL & TOMO XIII & 2019 & Página 83
\end{tabular}




\section{EL PROBLEMA DE LA DETERMINACIÓN DEL NEXO CAUSAL EN LA RESPONSABILIDAD CIVIL POR DAÑOS MEDIOAMBIENTALES: DE LA CERTEZA CAUSAL A LA TEORÍA DE LA CAUSALIDAD COMPLEJA}

ambiental, no quedará sometido a la presunción. Asimismo, la ley establece que, si los actos de la empresa exigen control y que esta los ha superado durante el período de tiempo del daño, no ha lugar a la presunción ${ }^{116}$.

La ley también como último recurso al demandado, si las anteriores excepciones no resultan aplicables, que demuestre la existencia de otro factor capaz de causar el daño de acuerdo con las peculiaridades de caso ${ }^{117}$. Como bien puede observarse, con tantos supuestos de exclusión el sistema se presenta bastante limitado ${ }^{118}$.

Por otra parte, algunos autores pusieron de manifiesto que la ley no presenta la capacidad de aplicar la presunción a todos los daños, y es principalmente ineficaz en los daños que se manifiestan con considerables distancias entre el hecho y el efecto, es decir, los daños alejados del foco de emisión, ya que según la ley la víctima debe, por lo menos, probar la aptitud para causar el daño y esta debe ser cierta $^{119}$. En tales supuestos, la presunción establecida por la ley pierde toda su eficacia.

Alemania se encuentra entre los países precursores de una ley de responsabilidad medioambiental y su legislación sirvió como antecedente e inspiración de la Directiva 2004/35/CE sobre responsabilidad medioambiental ${ }^{120}$ y, consecuentemente, en la Ley de Responsabilidad Medioambiental española (LRMA). La mencionada ley establece un sistema de presunciones legales al crear una lista(Anexo III) de actividades típicamente peligrosas que responderán de forma objetiva, previendo específicamente que el juez entienda por presumido que la actividad causó el daño o amenaza inminente de causarlo ${ }^{121}$.

La idea de la presunción del nexo causal, señalado en el artículo 3.1,segundo párrafo LRMA establece, así como la Ley alemana, que se presume que una instalación es la causa

\footnotetext{
${ }^{116}$ GOMIS CATALÁ (1998), p. 168.

${ }^{117}$ MORATO LeITE\& ARAUJO AYALA (2011), p. 181.

${ }^{118}$ GOMIS CATALÁ (1998), p. 169.

${ }^{119}$ GIESBERTS, L. (1994), "Environmental liability for industrial installations in Germany" en International Business Lawyer. $\mathrm{N}^{\mathrm{o}} 1$, p. 15

${ }^{120}$ EsteVe PARDO, J. (2008), Ley de responsabilidad medioambiental: comentario sistemático. Marcial Pons, Madrid, p. 57.

${ }^{121}$ RUDA (2008), p.328.
} 


\section{EL PROBLEMA DE LA DETERMINACIÓN DEL NEXO CAUSAL EN LA RESPONSABILIDAD CIVIL POR DAÑOS MEDIOAMBIENTALES: DE LA CERTEZA CAUSAL A LA TEORÍA DE LA CAUSALIDAD COMPLEJA}

del daño cuya reparación se reclama si dicha instalación es capaz de causar el daño ${ }^{122}$. Sin embargo, esta presunción no es absoluta, al ser un sistema de presunción iuris tantum, permite que el demandado destruya la presunción si demuestra que ha utilizado las instalaciones adecuadamente o que existe otro factor capaz de causar el daño, tal y como determina la Ley alemana.

Es importante destacar que, como regla general, la LRMA determina que el nexo causal ha de probarse, haciendo una excepción a la regla cuando haya correspondencia entre el tipo de daño y el tipo de actividad desarrollada ${ }^{123}$, es decir, se presumirá en nexo de causalidad cuando la actividad sea apta a causa el daño que se pretende imputar.

Por otro lado, antes de la transposición de la Directiva Europea al Derecho Español, los Tribunales Penales ya se demostraban a favor de un sistema de presunción del nexo, como en el "Caso Patel". La empresa "Sociedad Agraria Patel" vertió en las aguas del tramo final de la Riera de Sant Martí elementos tóxicos y contaminantes continuadamente desde el año $1968^{124}$. El tramo de la Riera comunicaba a más de 150 metros con el pantano de Sau, destino final de los vertidos, y del que se aprovecha sus aguas para el consumo humano. En el año 1996 se comprueba la turbiedad, putrefacción y eutrofización ${ }^{125}$ de las aguas y también se comprueba la disminución de la fauna marina, ya que el amoníaco, principalmente en su forma no ionizada, es tóxico para los peces.

En el año 1995 se había tomado muestras de las aguas en el punto del vertido de la empresa Patel que demostraban que la empresa no cumplía con los parámetros legales establecidos. En 2002 la Audiencia Provincial de Barcelona condenó a la empresa por un delito contra el medio ambiente. La empresa recurrió en casación alegando que no se había demostrado que los vertidos habían creado un peligro grave para las personas y los recursos naturales, ya que las muestras se tomaron en el punto del vertido y que el impacto sobre el medio ocurrió

\footnotetext{
${ }^{122}$ Gomis CAtAlÁ, L. (2008), "La Ley de responsabilidad medioambiental en el marco del derecho de la Unión Europea" en LOZANO CUTANDA, Comentarios a la Ley de responsabilidad medioambiental. Aranzadi, Navarra, p. 121.

${ }^{123}$ ÁlvareZ LATA (2014), p.1130.

${ }^{124}$ Sentencia del Tribunal Supremo, Sala 2a , de 08 de noviembre de 2004

${ }^{125}$ Según la Sentencia, la eutrofización es la proliferación excesiva de algas en aguas dulces.
}

\begin{tabular}{llll}
\hline \hline ANUARIO DE DERECHO CIVIL & TOMO XIII & 2019 & Página 85
\end{tabular}




\section{EL PROBLEMA DE LA DETERMINACIÓN DEL NEXO CAUSAL EN LA RESPONSABILIDAD CIVIL POR DAÑOS MEDIOAMBIENTALES: DE LA CERTEZA CAUSAL A LA TEORÍA DE LA CAUSALIDAD COMPLEJA}

"aguas arriba y aguas abajo". La acusada sostenía también que "no se puede evaluar en concreto el impacto ambiental de los vertidos, pues se ignora cuál es la aportación contaminante de otras industrias cercanas".

La tesis del Tribunal Supremo sostiene que la suma de un nexo causal a otro ya en curso (sobre determinación) no tiene el efecto de excluir la relación de causalidad. En esos supuestos no sólo todas las condiciones serán consideradas causas del resultado (condicio sine qua non), sino que, además, todas las causas que son posibles, es decir, aptas de producir el daño, serán objetivamente imputables.

Esta sentencia es un claro ejemplo de cómo los daños medioambientales deberían ser apreciados por los tribunales, ya que lo único que se requiere es establecer si la acción tiene la aptitud para generar tal daño, inclusive cuando el vertido sea en zonas ya contaminadas. La finalidad de la norma no es sólo evitar la contaminación, sino también impedir el incremento de la contaminación existente.

Esta solución también nos parece apropiada para casos de daños medioambientales en que hay distancia entre el lugar de la acción y el lugar del resultado, así como en los casos de múltiples fuentes de emisión, múltiples actores o supuestos en los que hay una larga distancia temporal entre la acción y el resultado (daños tardíos).

\subsection{La aplicación de teoría de la causalidad alternativa}

En materia general de responsabilidad civil, el BGB, en su artículo o $\S 830$ utiliza el modelo holandés de la causalidad alternativa, es decir, en caso de incerteza sobre la autoría del daño, cuando hay actuación conjunta de dos o más agentes, todos serán solidariamente responsables, si hay al menos, según el artículo, la seguridad que la acción de cada uno podría haber causado el daño.

La teoría de la causalidad alternativa ${ }^{126}$-alternative liability rule -prevé que, en razón del número elevado de posibles culpables, la víctima no necesita demostrar el nexo de

\footnotetext{
${ }^{126}$ Vease MúRTUla LAFUENTE. V. (2006), “Causalidad alternativa e indeterminación del causante del daño en la responsabilidad civil”, en Indret: Revista para el Análisis del Derecho, 2/2006. (www.indret.com)
}
ANUARIO DE DERECHO CIVIL
TOMO XIII
2019
Página 86 


\section{EL PROBLEMA DE LA DETERMINACIÓN DEL NEXO CAUSAL EN LA RESPONSABILIDAD CIVIL POR DAÑOS MEDIOAMBIENTALES: DE LA CERTEZA CAUSAL A LA TEORÍA DE LA CAUSALIDAD COMPLEJA}

causalidad directo con el agresor, sino que todos los posibles culpables integran la demanda como litisconsortes pasivos. Valiéndose de tal teoría, aunque no se sepa el actor efectivo del daño, los potencialmente actores están obligados a indemnizar solidariamente.

La teoría fue aceptada e introducida en el Código Civil holandés en el artículo 99 del libro 6, claramente inspirado en el caso norteamericano Summers v. Ticeen $1948^{127}$ donde una persona resultó herida cuando dos cazadores (Tice y Simonson) dispararon descuidadamente en su dirección y a pesar de que el actor no pudo identificar cuál de los cazadores había causado realmente la lesión, el Tribunal de California consideró que había $50 \%$ de probabilidades que fuera uno $\mathrm{u}$ otro, condenando a ambos a responder solidariamente.

La legislación holandesa ${ }^{128}$ establece que, si el daño es consecuencia de dos o más acontecimientos y cada acontecimiento tiene un autor, si se ha podido verificar que el daño se ha provocado por alguno de estos hechos, los autores tienen la obligación de indemnizar, salvo que puedan demostrar que el daño no fue provocado por su conducta.

De forma muy similar, el Código Civil de Austria (ABGB), §1.304, propone el uso de la causalidad alternativa en casos en que hay más de una posible causa para determinar el daño y no es posible determinar cuál de ellas es la causa ${ }^{129}$. Por otro lado, en países latinos como Brasil, el criterio fue aplicado pocas veces por la jurisprudencia, entendiendo que solamente en algunos supuestos cuando no se puede determinar con exactitud el responsable y hay una pluralidad de posibles causantes. La responsabilidad solidaria pasiva, utilizando el artículo 942 del Código Civil brasileño, establece que habiendo más de un actor causador del daño todos serán responsables solidariamente por la reparación, sin embargo, no es criterio dominante.

En España, la responsabilidad solidaria es el criterio utilizado por la jurisprudencia para los

\footnotetext{
${ }^{127}$ SHEFFET, M.J. (1983) "Market Share Liability: A new doctrine of causation in product liability" enJournal of Marketing, V. 47 p. 37

${ }_{128}$ Artículo 102 del libro sexto del Código Civil holandés (6:102 BW)

${ }^{129}$ OLIPHANT, K. (2016) "Causation in cases of evidential uncertainty: juridical techniques and fundamental issues" en Chicago-Kent Law Review, V. 91, ed. 2, p. 600.
} 


\section{EL PROBLEMA DE LA DETERMINACIÓN DEL NEXO CAUSAL EN LA RESPONSABILIDAD CIVIL POR DAÑOS MEDIOAMBIENTALES: DE LA CERTEZA CAUSAL A LA TEORÍA DE LA CAUSALIDAD COMPLEJA}

casos donde dos o más personas han causado el daño, pero es imposible determinar la cuota de responsabilidad de cada uno ${ }^{130}$. Así la cosas, la víctima puede demandar a uno, varios o a todos los responsables solidarios. Prueba de ello es la Sentencia del Tribunal Supremo de 28 de abril de 1992, sobre daños por pérdida de aguas, donde el TS condenó solidariamente a los demandados porque no era posible individualizar los comportamientos de los agentes y sus respectivas responsabilidades ${ }^{131}$. De igual forma, la sentencia de la Sala $3^{\text {a }}$ de 6 de marzo de 1998, consideró que cuando no haya relación exclusiva con un agente, todos los responsables deben pagar en proporción la indemnización.

En definitiva, utilizar la teoría de causalidad alternativa es una forma de flexibilizar la prueba causal cuando se presenta más de un posible actor y estamos en sede de responsabilidad subjetiva. Por ello, solo se aplica en casos específicos en que 1) se constate un daño que puede haber sido provocado por uno u otro agente, 2) sea culposo 3) no se pueda demostrar cuál de ellos ha sido el efectivo causante. Es importante advertir que la teoría no modifica la carga probatoria de manera automática y tampoco retira la necesidad de probar la relación causal, sino tan sólo atenúa la necesidad de individualizar la cuota de contribución al daño de cada demandado y establece la responsabilidad solidaria.

Esta importante "herramienta" de flexibilización preconiza la necesidad inalienable de reparar el medioambiente, pero no resuelve los demás problemas relacionados con la casualidad compleja sino el de múltiples agentes. Por ello, es necesario analizar las formas encontradas en la doctrina y en la jurisprudencia, para que actúen solas o se sumen a las ya presentadas.

\footnotetext{
${ }^{130}$ SALVADOR CODERCH, P. ET AL. (2014), “Daños Tardíos" en InDret1/2014, p. 24

${ }^{131}$ STS de 28 de abril de 1992: se produce solidaridad entre los sujetos a quienes alcanza la responsabilidad por el ilícito culposo, con pluralidad de agentes y concurrencia causal única, cuando no es posible individualizar los respectivos comportamientos ni establecer las respectivas responsabilidades
} 


\section{EL PROBLEMA DE LA DETERMINACIÓN DEL NEXO CAUSAL EN LA RESPONSABILIDAD CIVIL POR DAÑOS MEDIOAMBIENTALES: DE LA CERTEZA CAUSAL A LA TEORÍA DE LA CAUSALIDAD COMPLEJA}

\subsection{La doctrina de la cuota de mercado del Derecho de daños norteamericano (share market liability)}

Aunque la prueba de la causalidad en el common law se caracterice por ser menos exigente, ya que se utiliza el criterio de la probabilidad causal para imputar responsabilidad, o sea, el juez puede considerar probada en su totalidad la relación de causalidad en circunstancias en las que posiblemente los tribunales españoles consideraría la falta de prueba de dicho presupuesto $^{132}$, esta flexibilización no fue suficiente para resolver todas las dificultades planteadas por la prueba del nexo de causal, por lo que en los años ochenta surgió una teoría - market share liability theory- para flexibilizar el nexo en casos extremos de daños causados por múltiples agentes.

De forma muy resumida, en el leading case Sindell que da lugar a la aplicación de la aludida teoría, las víctimas desarrollaron deformación en el útero, ciertos tipos de tumores y cierto riesgo de desarrollar cáncer de mama debido a un medicamento suministrado a las madres durante el embarazo ${ }^{133}$. Quedó demostrado por diversas investigaciones que la medicación $D E S$ - un sintetizador de estrógeno artificial - era el causante de dichos daños y que afectaría a la descendencia de las víctimas, Sin embargo, existía un problema técnico de índole probatoria, pues más de 200 laboratorios ${ }^{134}$ fabricaban la aludida medicación, y era imposible determinar cuál marca de laboratorio específicamente fabricó el medicamento que habían consumido las madres de las víctimas.

Aunque no fue probada la relación de causalidad entre el daño y la acción individual de los demandados, el tribunal californiano decidió repartir la indemnización acorde con la participación en el mercado de cada empresa productora de medicamento, aplicando así la teoría de la cuota de mercado, propuesta originalmente por un estudiante en el año $1978^{135}$.

\footnotetext{
${ }^{132}$ SolÉ Feliu, J. (2018), "Mecanismos de flexibilización de la prueba de la culpa y del nexo causal en la responsabilidad civil médico-sanitaria" en Revista de Derecho Civil, Vol. 5, nº 1, p.60.

${ }^{133}$ RoBINSON, G. O. (1982), "Multiple causation in tort law: reflections on the DES cases", Virgina Law Review, $\mathrm{n}^{\circ}$ 4, V 68, 1982. p. 714.

${ }^{134}$ SHEFFET (1983), p. 39.

${ }^{135}$ RUDA GONZÁLEZ, A. (2003) "La responsabilidad por cuota de mercado a juicio" en Indret: Revista para el Análisis del Derecho, Nº. 3, 2003, p. 4.
} 


\section{EL PROBLEMA DE LA DETERMINACIÓN DEL NEXO CAUSAL EN LA RESPONSABILIDAD CIVIL POR DAÑOS MEDIOAMBIENTALES: DE LA CERTEZA CAUSAL A LA TEORÍA DE LA CAUSALIDAD COMPLEJA}

Utilizando la teoría de la cuota de mercado, el juez determinó que el demandante no necesita mostrar cuál de los fabricantes le causó directamente la lesión, tampoco si contribuyó o no directamente a la lesión, aplicando responsabilidad a todos los laboratorios en proporción a la cantidad de medicamente que pusieron en venta por el hecho de estar en el mercado ${ }^{136}$.

Este caso fue estudiado - y todavía lo es - en el ámbito de responsabilidad por producto defectuoso ${ }^{137}$, donde fueron desarrollados criterios y requisitos para su aplicación, sin embargo, pensando en el ámbito medioambiental, ¿sería posible utilizar la cuota de mercado para imputar la obligación de reparar a todos los sujetos que desarrollen determinada actividad relacionada con el daño ecológico sufrido?

¿Sería una alternativa cuando estamos delante de casos de múltiples agentes e imposibilidad de identificación o individualización del agente? Así, cuando no sea posible demostrar cuál de las industrias puestas en liza causó el daño ecológico, todas las que las que desarrollen actividades contaminantes similares y estén en la esfera del daño ecológico y tengan las condiciones de provocar el daño deberán ser responsables en la proporción a sus respectivas actividades.

El caso clásico es la contaminación por emisión de gases en zonas industriales, ya que es científicamente imposible establecer cuál es la industria exacta que causó determinada contaminación, pero sí se puede calcular las emisiones de gases de efecto invernadero (GEI) asociadas al consumo de energía, tanto en instalaciones fijas como de transporte y fijar proporción de emisión de cada agente.

No se trata de la regla de la responsabilidad solidaria entre los posibles agentes, como acontece en el caso de la causalidad alternativa, sino de una regla que prevé una responsabilidad parciaria o fraccionada de cada sujeto agente en función de su cuota de

\footnotetext{
${ }^{136}$ RoBINSON (1982), p. 721.

${ }^{137}$ Véase: GoldBERG, R. (1999) Causation and Risk in the Law of Torts: Scientific Evidence and Medicinal Product Liability, Hart, Oxford, Portland Oregon. GóMEZ-LA PLAZA, M.C (2000), "La responsabilidad por los daños causados por productos defectuosos en la Unión Europea. Presente y futuro", en Aranzadi Civil, págs. 2327-2353.
} 


\section{EL PROBLEMA DE LA DETERMINACIÓN DEL NEXO CAUSAL EN LA RESPONSABILIDAD CIVIL POR DAÑOS MEDIOAMBIENTALES: DE LA CERTEZA CAUSAL A LA TEORÍA DE LA CAUSALIDAD COMPLEJA}

potencial lesivo. Por lo tanto, la responsabilidad se atribuye por su cuota y según su cuota. De hecho, la doctrina defiende que idea de solidaridad pura y simple no es la mejor solución en materia ambiental, pero sí la aplicación la responsabilidad por cuota de mercado, lo que ya se conoce con el nombre de pollution share liability ${ }^{138}$

La crítica que se hace a esta teoría es la posibilidad de que evolucione hacia una especie de teoría de responsabilidad objetiva agravada ${ }^{139}$ generalizada, donde el demandado solo puede alegar causas tasadas de fuerza mayor, tal y como ocurre en la responsabilidad por actividades peligrosas, donde basta la prueba de que el daño es derivado del riesgo propio de la actividad. ${ }^{140}$

\section{Conclusiones: críticas al actual sistema de responsabilidad medioambiental en lo que se refiere al nexo causal y propuesta de lege ferenda.}

En la revolución industrial la teoría del riesgo fue instrumento para garantizar la reparación del medioambiente, sin embargo, la constante evolución de la tecnología y la globalización exigen del operador del derecho pensar en nuevas construcciones teóricas para garantizar la efectiva responsabilidad civil derivada de daños ecológicos. La consagración de la responsabilidad civil objetiva y la presunción de causalidad en la Ley de Responsabilidad Medioambiental (LRMA), aunque solo para las actividades del Anexo III,es apenas el comienzo de un largo camino de flexibilización, de facilitar la imputación de responsabilidad civil a los sujetos que degradan el entorno ambiental.

La complicada relación causa y efecto de los daños medioambientales (vid. 2) exige poner el enfoque en su prueba, ya que un modelo adecuado a la tutela del medio ambiente depende de la atenuación de esta. En efecto, la necesidad de probar la razonable existencia del nexo de causalidad, aplicando criterios de probabilidad, es un paso previo para

\footnotetext{
${ }^{138}$ DíEZ-PiCAZo GiMÉnEZ, G. (1996) "La responsabilidad civil derivada de los daños al medio ambiente”, en La Ley: Revista jurídica española de doctrina, jurisprudencia y bibliografía, no 5, 1996, p. 1420.

${ }^{139}$ NORONHA, F. (1999), "Desenvolvimentos contemporâneos da responsabilidade civil” em Revista dos Tribunais, ano 88, V. 761, março. São Paulo. p. 37

${ }^{140}$ BASOZA BALARrue, X. (2015) Responsabilidad extracontractual objetiva: parte general. BOE, Madrid. p.51.
} 


\section{EL PROBLEMA DE LA DETERMINACIÓN DEL NEXO CAUSAL EN LA RESPONSABILIDAD CIVIL POR DAÑOS MEDIOAMBIENTALES: DE LA CERTEZA CAUSAL A LA TEORÍA DE LA CAUSALIDAD COMPLEJA}

transferir al demandado el deber de aportar las pruebas que fundamenten su alegación sobre la inexistencia del nexo causal, es decir, la inversión de la carga de proba relativa al nexo.

Para alejar el elemento "certeza" del nexo y aplicar el criterio de "probable", se parte de ambos conceptos de causalidad, fáctica y jurídica (vid.1.2). Es decir, primero en materia de causalidad fáctica, aplicar el criterio de probabilidades y consecuentemente el sistema de presunciones iuris tantum. De este modo, se proyecta al demandado la obligación de probar la inexistencia del nexo de causalidad. En segundo lugar, en materia de causalidad jurídica, aplicar todos los criterios, desde causalidad adecuada hasta el fin de protección de la norma a través de un juicio de probabilidad ${ }^{141}$.

Es cierto que el Tribunal Supremo se manifestó a favor de aplicar el sistema de presunciones, incluso en materia penal ${ }^{142}$, pero usa un criterio de probabilidades lindando a la certeza, con un rigor más extremo de lo que el nexo causal entre la conducta y daños ecológicos suele demostrar. El criterio de probabilidades debe ser entendido como la considerable presencia del nexo entre los residuos/contaminaciones y el daño sufrido ${ }^{143}$, entendiendo "considerable" a criterio del juez, pero que estén puestas de manera vinculante $^{144}$. Es decir, que la dogmática civil acoja definitivamente estos criterios y que sirva a su finalidad última: reparar el medioambiente.

En definitiva, reiteramos que no se trata prescindir del nexo causal, pero de utilizar instrumentos capaces de atenuar su prueba con el fin de no sucumbir al fenómeno de la “causalidad compleja” y dejando, en consecuencia, el medio ambiente sin reparación. En

${ }^{141}$ El juicio de probabilidad en materia de causalidad jurídica puede ser contemplado por los ordenamientos jurídicos, con reglas especiales más relajadas en materia de prueba causal, tal y como lo hace Alemania en su ley de enjuiciamiento civil (\$287 ZPO) acerca de la determinación y cuantificación del daño. Haciendo una diferenciación entre causalidad primaria y secundaria, el magistrado puede hacer un juicio de probabilidad sustancial de la causalidad secundaria. Pese a que, la causalidad material, lo que la ley alemana llama de causalidad primaria, exija un riguroso estándar general de prueba.

142 STS de 12 de mayo de 1986: La presunción judicial ha sido admitida, incluso, en el ámbito penal en determinadas circunstancias sin que con ello se vulnere la presunción de inocencia.

${ }^{143}$ GOMis CATALÁ (1998), p. 165.

${ }^{144}$ Es cierto que al magistrado toca la tarea de encontrar el punto de equilibrio entre la demonstración de los requisitos de la responsabilidad civil y la preservación medioambiental, pero también es imprescindible fornecer al magistrado mecanismos que permitan una actuación uniforme y la mejor forma de conseguir una legislación especial. 


\section{EL PROBLEMA DE LA DETERMINACIÓN DEL NEXO CAUSAL EN LA RESPONSABILIDAD CIVIL POR DAÑOS MEDIOAMBIENTALES: DE LA CERTEZA CAUSAL A LA TEORÍA DE LA CAUSALIDAD COMPLEJA}

este sentido, la jurisprudencia inglesa ha entendido que no cabe exigir al demandante una prueba del nexo causal en los casos en que es imposible científicamente demostrarlo ${ }^{145}$, lo que nos traslada a la idea de presunción de la relación causal.

Se hace más que necesario que la responsabilidad civil se ajuste a las nuevas realidades y dé soluciones eficaces a los problemas que se plantean en la sociedad moderna, caracterizada por la masificación, el consumismo y la tecnología. ${ }^{146}$ Reafirmamos que el sistema de responsabilidad civil medioambiental debe estar atento a sus singularidades, así como lo es para los daños causados por circulación de vehículos a motor, para los productos defectuosos, los daños causados por navegación aérea, entre otros.

\section{Bibliografía}

Álvarez LATA, N.(2014), "Responsabilidad Civil por daños al medio ambiente" en Reglero Campos, F \& Busto Lago, J.M. Tratado de Responsabilidad Civil, tomo II, $4^{\text {a }}$ ed. Aranzadi, Navarra. pp. 1100-1196.

Avilés García, J. (2016), Comentario a la Sentencia de 20 de octubre de 2015 (RJ 2015, 4226). Revista Cuadernos Civitas de Jurisprudencia Civil num. 101/2016. Editorial Civitas, SA, Pamplona.

Arcos VieIRA, Ma . A. (2005), Responsabilidad civil: nexo causal e imputación objetiva en la jurisprudencia. Aranzadi, Navarra.

BasozabalArrue, X. (2015) Responsabilidad extracontractual objetiva: parte general. BOE, Madrid.

BECK, U. (2002), La sociedad del riesgo global. Siglo Veintiuno de España Editores, Madrid.

Benjamin, A. H.V. (1998), "Responsabilidade Civil pelo Dano Ambiental" en Revistade Direito Ambiental, n. 9/5, jan-mar, São Paulo, págs. 75-136.

${ }^{145}$ Caso de daños por inhalación de asbesto: Fairchild vs. Glenhaven Funeral Services. Véase RUDA (2008), p.306

${ }^{146}$ Múrtula Lafuente (2006), p. 23. 


\section{EL PROBLEMA DE LA DETERMINACIÓN DEL NEXO CAUSAL EN LA RESPONSABILIDAD CIVIL POR DAÑOS MEDIOAMBIENTALES: DE LA CERTEZA CAUSAL A LA TEORÍA DE LA CAUSALIDAD COMPLEJA}

Bescovitz Rodriguez-CANo, R. (DIR) (2010), Responsabilidad extracontractual. Aranzadi, Navarra.

BonORINO, P. \& LEAL, V. (2010), "La prueba de la causalidad en el daño ambiental" en Avances en ciencias de la tierra, nº 1, págs. 39-52.

CABAnIllas SÁNCHEZ, A. (1990) “La responsabilidad por daños ambientales según la jurisprudencia civil” en Revista de Derecho Ambiental, n 6, págs. 83-104.

ambiental, $\mathrm{n}^{\circ} 12$, págs. 9-28.

(1994),"El daño ambiental” en Revista de derecho

(2017), "Los criterios de imputación de la responsabilidad medioambiental” en EMBID Irujo, J.M., MiQuel GonZÁleZ, J.M. \& MorAlES Moreno, A.M (dir) Estudios jurídicos: Liber Amicorum en honor a Jorge Caffarena. Colegio de Registradores de la Propiedad y Mercantiles de España, Madrid, págs. 181-201.

Cafferatta, N. A. (2008), "Prueba y nexo de causalidad en el daño ambiental" en: Memorias del $6^{\circ}$ Encuentro Internacional de Derecho Ambiental. Foro Consultivo Científico y Tecnológico, México, págs. 51-106.

CAÑIZARes LAso, A. Y Rodríguez TAPIA, J.M. (1994), La nueva regulación alemana en materia de responsabilidad por daños causados al medio ambiente" en Anuario de Derecho Civil, Tomo XLVII Fascículo I. Publicado por Ministerio de Justicia, Madrid, págs. 209 y ss.

CORDero Lobato, E. (2002), "Derecho de daños y medio ambiente". en: OrTeGA Alvarez, L. (coord.) Lecciones de Derecho de Medio Ambiente, Lex Nova. págs. 509532.

CortésDomínguez, V. \& Moreno Catena, V. (2017), Derecho procesal civil. Parte General. $8^{\mathrm{a}}$ ed. Tirant lo Blanch, Valencia, págs. 211-227.

DAmián Moreno, J. (2007), "Nociones generales sobre la carga de la prueba en el proceso civil” en CORTÉS DOMÍNGUEZ, V.Carga de la prueba y responsabilidad civil. Tirant lo Blanch, Valencia, págs. 13-27.

De ANGEL YÁGÜEZ, R.(1995), Algunas previsiones sobre el futuro de la responsabilidad civil (con especial atención a la reparación del daño) Editorial Civitas, Madrid.

(2008), "Elementos o presupuestos de la responsabilidad civil (III) la relación de causalidad” en Sierra Gil de la Cuesta, I.y DE ANGEL YÁGÜEZ, R. 


\section{EL PROBLEMA DE LA DETERMINACIÓN DEL NEXO CAUSAL EN LA RESPONSABILIDAD CIVIL POR DAÑOS MEDIOAMBIENTALES: DE LA CERTEZA CAUSAL A LA TEORÍA DE LA CAUSALIDAD COMPLEJA}

(2008),Tratado de la responsabilidad civil. Tomo I, Editorial Bosch, Barcelona, págs. 413511.

De Cossio, A. (1966), "La causalidad en la responsabilidad civil: estudio del Derecho Español” em Anuario de Derecho Civil, Vol. 19, nº 3, págs. 527-554.

De Cuevillas MatozzI, I. (2000),La relación de causalidad en la órbita del derecho de daños. Tirant lo Blanch, Valencia.

De Miguel Perales, C. (1994),La responsabilidad civil por daños al medio ambiente. Civitas, Madrid.

Madrid.

(2002), Derecho español del medio ambiente. 2ed. Civitas,

DíAZ-REgAÑón GARCíA-AlCALÁ, C. (2003), "Relación de causalidad e imputación objetiva en la responsabilidad civil sanitaria" en Indret, $\mathrm{n}^{\circ}$ 1/2004. (www.indret.com)

DíEz-PicAzo, L. (2011), Fundamentos del derecho civil patrimonial, Vol V: La responsabilidad civil extracontractual. Aranzadi, Navarra.

DíEZ-PICAZo GimÉnEZ, G.(1996), "La responsabilidad civil derivada de los daños al medio ambiente", en La Ley: Revista jurídica española de doctrina, jurisprudencia y bibliografía, № 5, 1996, págs. 1419-1421.

ELLIOTT, D. (1988), "Torts with multiple causes under U.S Law" en FENYVES Y WEYERS,MultikausaleSchaden in modernenHaftungsrechten. a.M Metzner, Frankfurt, págs. 9-32.

EsteVe PARDO, J. (2008), Ley de responsabilidad medioambiental: comentario sistemático. Marcial Pons, Madrid, págs. 55-66.

FACH Gómez, K. (2002), La contaminación transfronteriza en derecho internacional privado. Editorial Bosch, Barcelona.

FindLEY, R.(1996), "Civil liability and protection of environmente in the United States". En Revista de Ciência e Cultura, Porto.

FLEMING, J. (1998), The law of torts. The law book company, $9^{\mathrm{a} e d, ~ S y d n e y . ~}$

GIESBERTS, L. (1994), "Environmental liability for industrial installations in Germany" en International Business Lawyer. $\mathrm{n}^{\circ}$ 1, págs.14-19. 


\section{EL PROBLEMA DE LA DETERMINACIÓN DEL NEXO CAUSAL EN LA RESPONSABILIDAD CIVIL POR DAÑOS MEDIOAMBIENTALES: DE LA CERTEZA CAUSAL A LA TEORÍA DE LA CAUSALIDAD COMPLEJA}

GoldBerg, R. (1999),Causation and risk in the law of torts: scientific evidence and medicinal product liability, Hart, Oxford, Portland Oregon.

Goldenberg, I. \&CAFFERATTA, N. (2001), Daño ambiental: problemática de su determinación causal. Abeledo-Perrot, Buenos Aires.

Gómez Benítez, J.M. (1998), Causalidad, imputación y calificación por el resultado, Ministerio de Justicia, Secretaria General Técnica, Centro de Publicaciones, Madrid.

GóMEZ-LAPlAZA, M.C (2000), "La responsabilidad por los daños causados por productos defectuosos en la Unión Europea. Presente y futuro”, en Aranzadi Civil, págs. 2327-2353.

Gomis Catalá, L. (1998), Responsabilidad por daños al medio ambiente. Arazandi, Navarra.

(2008), "La Ley de responsabilidad medioambiental en el marco del derecho de la Unión Europea" en Lozano CutAndA, B., Comentarios a la Ley de responsabilidad medioambiental. Aranzadi, Navarra, págs. 83-146.

HART, H \&HonorÉ, T. (1985), Causation in the Law, Oxford, Clarendon Press.

Harpwood. V. (2003), Modern Tort Law. Cavendish, London, $5^{\text {a }}$ ed.

INFANTE RUíz, F. J. (2002), La responsabilidad por daños: Nexo de causalidad y "causas hipotéticas" Tirant lo blanch, Valencia.

INFANTINO, M. (2013), "Il diritto comparato della causalità aquiliana", en Rivista di diritto civile. No. 3. CEDAM, Padua, págs. 569-589.

LunA Yerga, A. (2004), La prueba de la responsabilidad civil médico-sanitaria. Civitas, Madrid.

Martín-CASAls, M. (COORD.) (2008), Principios de derecho europeo de la responsabilidad civil. Aranzadi, Navarra.

Martín CASAls, M. y SolÉFeliu, J. (2004), "Multiple tortfeasors under Spanish Law" en ROGERS (ed). Unification of tort law: multiple tortfeasors. Kluwer Law Int, The Hague, págs. 189-213.

(2011), "La modernización del Derecho de la responsabilidad extracontractual" en Cuestiones actuales en materia de Responsabilidad Civil.XV Jornadas APDC, Editum, Murcia, págs. 11-111. 


\section{EL PROBLEMA DE LA DETERMINACIÓN DEL NEXO CAUSAL EN LA RESPONSABILIDAD CIVIL POR DAÑOS MEDIOAMBIENTALES: DE LA CERTEZA CAUSAL A LA TEORÍA DE LA CAUSALIDAD COMPLEJA}

Morato Leite, J.R \&Araujo Ayala, P. De (2011), Dano ambiental: do individual ao extrapatrimonial. Teoria e prática. 3. ed. Revista dos Tribunais, São Paulo.

Moscoso Restovic, P.M. (2010), "Competencia judicial civil internacional por daño ambiental: determinación del hecho dañoso y su extensión. El caso europeo”, en Foro, Nueva época, no 11-12, págs. 193-229.

Mullis A. y OliPhant K. (1993), Causation. en Torts. Macmillan Professional Masters. Palgrave, London, págs.79-88

Múrtula LAFUENTE. V. (2006), "Causalidad alternativa e indeterminación del causante del daño en la responsabilidad civil”, en Indret, n²/2006. (www.indret.com)

NAVArro-Michel, M. (2016), "Daños causados por la Talidomida. La batalla legal que no cesa. Comentario a la STS de 20 de octubre de 2015" en Revista Bioética y Derecho n $^{\circ}$ 37, Barcelona.

NorONHA, F.(1999), "Desenvolvimentos contemporâneos da responsabilidade civil" em Revista dos Tribunais, nº 88, V. 761-mar, São Paulo.págs. 31-44

Oliphant, K. (2007), "The nature of tortious liability" enThe law of tort. LexisNexi, Londres, págs, 1-38.

(2016), "Causation in cases of evidential uncertainty: juridical techniques and fundamental issues" en Chicago-Kent Law Review, V. 91, ed. 2, págs. 587-602.

PAlao Moreno, G. (1998) La responsabilidad civil por daños al medio ambiente. Tirant lo Blanch, Valencia.

PANTAleón Prieto, F.(1990), “Causalidad e imputación: criterios de imputación”, en Centenario del Código Civil (1889-1989), Tomo II, Centro de estudios Ramon Areces, Madrid, págs. 1561-1592.

(1991), "Comentario al art. 1902 CC", en Comentario del Código civil. Ministerio de Justicia, Tomo II, Centro de Publicaciones, Madrid, págs. 19712003.

PARRA LuCÁN, M.A. (1991), "Responsabilidad por los daños producidos como consecuencia de la contaminación de las aguas" en Poder Judicial, n 21, págs. 107-112.

PÉREZ Fuentes, G. M. (2009), "La responsabilidad civil por daños al medio ambiente en el derecho comparado" en Prolegómenos. Derechos y Valores. V. XII, № 23, págs. 35-42 


\section{EL PROBLEMA DE LA DETERMINACIÓN DEL NEXO CAUSAL EN LA RESPONSABILIDAD CIVIL POR DAÑOS MEDIOAMBIENTALES: DE LA CERTEZA CAUSAL A LA TEORÍA DE LA CAUSALIDAD COMPLEJA}

PINHO, M. J. S. (2013), “Educação ambiental, cultura corporal e práxis pedagógica escolar: histórias e memórias de uma comunidade rural da Bahia". Em Repositorio Faculdade de Educação, Universidade Federal da Bahia, Salvador.

Prevot, J. M. (2010), "El problema de la relación de causalidad en el derecho de la responsabilidad civil” en Revista Chilena de Derecho Privado, No 15, págs. 143-178.

ReYes LÓPEZ, M. J. (coord.) (2001), Derecho Ambiental Español. Tirant lo Blanch, Valencia. págs. 187-258

Robinson, G. O. (1982), "Multiple causation in tort law: reflections on the DES cases", Virginea Law Review, Nº 4, V 68, 1982. págs. 713-769

Roca Trías, E. \& Navarro Michel, M. (2016), Derecho de daños. Textos y materiales, $7^{\mathrm{a}}$ ed, Tirant lo blanch, Valencia.

RoGELVIDE, C. (1979), "Responsabilidad civil extracontractual, culpa objetiva o por riesgo. Falta y relación de causalidad. Inversión de la carga de la prueba" en Anuario de derecho civil, Vol. 32, nº 1, págs. 267-280

Rosenberg, L. (2002), La carga de la prueba. Editora BdeF, Buenos Aires.

RoxIN, C. (2002), Funcionalismo e imputação objetiva no direito penal. 3.ed. Renovar, Rio de Janeiro.

RudA GonZÁlez, A. (2008), El daño ecológico puro: La responsabilidad civil por el deterioro del medio ambiente, con especial atención a la Ley 26-2007, de 23 de octubre, de responsabilidad medioambiental. Aranzadi, Navarra.

$\mathrm{n}^{\mathrm{o}} .3,2003$. (www.indret.com)

. (2003), "La responsabilidad por cuota de mercado a juicio" en Indret,

Salvador Coderch, P. \& Fernández Crende, A. (2006), "Causalidad y responsabilidad ( $3^{\mathrm{a}}$ edición)",en InDret 1/2006. (www.indret.com)

Salvador Coderch, P.; GomézLiguerre, C.; Rubí Puig, A.; Ramos GonzÁlez, S. \& TERRA IBÁÑEZ, A. (2014), “Daños Tardíos” en InDret1/2014, (www.indret.com)

SANDS, P. \&STEWART, R. (1996), "Valuation of environmental damage US and international approches". enReview of European Community \& International Environmental law,V. 5, Oxford, p. 291 


\section{EL PROBLEMA DE LA DETERMINACIÓN DEL NEXO CAUSAL EN LA RESPONSABILIDAD CIVIL POR DAÑOS MEDIOAMBIENTALES: DE LA CERTEZA CAUSAL A LA TEORÍA DE LA CAUSALIDAD COMPLEJA}

Sierra Gil de la Cuesta, I.y De Angel YÁgüeZ, R.(coords.) (2008), Tratado de la responsabilidad civil. Tomo I, Editorial Bosch, Barcelona.

Solé FeliU, J. (2018), "Mecanismos de flexibilización de la prueba de la culpa y del nexo causal en la responsabilidad civil médico-sanitaria" en Revista de Derecho Civil, Vol. 5, no. 1, págs. 55-97.

SHEFFET, M.J.(1983), "Market Share Liability: A new doctrine of causation in product liability", enJournal of Marketing, V. 47. págs. 35-43.

SheEHAN, L. (1991), “The EEC's Proposed Directive on Civil Liability for Damage Caused by Waste: Taking Over When Prevention Fails" en Ecology Law Quarterly, University of California, Berkeley Vol. 18, No. 2, págs. 405-458

VAQUeRo PINTO, M. J. (2006), "Responsabilidad civil por daños ambientales", en: Revista de Derecho Privado, año 90, mayo-junio, págs. 35-62.

WinTER, G. (1994), German environmental law: basisc texts, an introduction. Martins Nijhol, Dordrecht.

Wright, R. (1985), “Causation in Tort Law” en Califonia Law Review. V. 73, ed 6. págs. $1735-1828$.

YAnguas Montero, G. (2006), El daño no patrimonial en el derecho del medio ambiente. Editorial Aranzadi, Navarra.

YzQuiERdo Tolsada, M. (2017), Responsabilidad Civil Extracontractual. Parte general. 3 ed. Dykison, Madrid, págs. 205-248.

Tabla de jurisprudencia citada

\begin{tabular}{|c|c|c|c|}
\hline Tribunal, Sala y Fecha & $A r$. & Magistrado Ponente & Partes \\
\hline STS, $1^{\mathrm{a}}, 22.02 .1946$ & RJ 51 & José Molina Candelero & 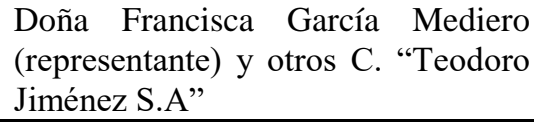 \\
\hline STS, $1^{\mathrm{a}}, 28.06 .1979$ & RJ 2553 & $\begin{array}{l}\text { José Beltrán de Heredia y } \\
\text { Castaño }\end{array}$ & $\begin{array}{l}\text { Don Adolfo L. F. c. "Unión Agrícola } \\
\text { Azucarera de Nuestra Señora del } \\
\text { Carmen" }\end{array}$ \\
\hline STS, $1^{\mathrm{a}}, 19.06 .1980$ & RJ 2410 & Jaime Santos Briz & $\begin{array}{l}\text { Don Enrique c."Cía. Naviera } \\
\text { Empresa Nacional Elcano de la } \\
\text { Marina Mercante, S.A” y otros. }\end{array}$ \\
\hline STS, $1^{\mathrm{a}}, 14.07 .1982$ & RJ 4237 & Carlos de la Vega Benayas & $\begin{array}{l}\text { Don Joaquín L. A c. "Dolomitas del } \\
\text { Norte, S. A.", y "Veriña, S. A" }\end{array}$ \\
\hline STS, $2^{\mathrm{a}}, 12.05 .1986$ & RJ 2452 & $\begin{array}{l}\text { Ramón Montero Fernández- } \\
\text { Cid }\end{array}$ & Marina R. J. \\
\hline
\end{tabular}




\section{EL PROBLEMA DE LA DETERMINACIÓN DEL NEXO CAUSAL EN LA RESPONSABILIDAD CIVIL POR DAÑOS MEDIOAMBIENTALES: DE LA CERTEZA CAUSAL A LA TEORÍA DE LA CAUSALIDAD COMPLEJA}

\begin{tabular}{|c|c|c|c|}
\hline STS, $1^{\mathrm{a}}, 05.04 .1988$ & RJ 2652 & José Luis Albácar López & $\begin{array}{l}\text { Don Miguel Angel G. S., contra Don } \\
\text { Marcelino M. R. y la "Forjados } \\
\text { Menéndez, S. A." }\end{array}$ \\
\hline STS, $1^{\mathrm{a}}, 13.06 .1988$ & RJ 4872 & $\begin{array}{l}\text { Manuel González Alegre y } \\
\text { Bernardo }\end{array}$ & $\begin{array}{l}\text { "Piscifactoría del Río Marea S. A". } \\
\text { c. "Agromán, S. A." }\end{array}$ \\
\hline STS, 1 ${ }^{\mathrm{a}}, 16.01 .1989$ & RJ 101 & $\begin{array}{l}\text { Manuel González Alegre y } \\
\text { Bernardo }\end{array}$ & $\begin{array}{llllll}\text { Doña Sira B. } & \text { G. } & \text { e } & \text { hijo. } & \text { c. } \\
\text { "ENSIDESA" }\end{array}$ \\
\hline STS, 1 ${ }^{\mathrm{a}}, 27.10 .1990$ & RJ 8053 & $\begin{array}{l}\text { Gumersindo Burgos Pérez } \\
\text { de Andrade }\end{array}$ & $\begin{array}{lcccc}\begin{array}{l}\text { Don José Andrés } \\
\text { "RIOCASA, S. A" }\end{array} & \text { T. } & \text { G. } & \text { c. } \\
\end{array}$ \\
\hline STS, 2a 23.04 .1992 & RJ6783 & Enrique BacigalupoZapater & $\begin{array}{l}\text { Ministerio Fiscal - El caso "aceite } \\
\text { de colza" }\end{array}$ \\
\hline STS, 1 ${ }^{\mathrm{a}}, 28.04 .1992$ & RJ 4466 & Pedro González Poveda & $\begin{array}{llll}\text { "Celestino } & \text { Solano, } & \text { S.A" } & \text { c, } \\
\text { "Ayuntamiento de Logroño" } & \\
\end{array}$ \\
\hline STS, $1^{\mathrm{a}}, 14.02 .1994$ & RJ1468 & Pedro González Poveda & $\begin{array}{l}\mathrm{D}^{\mathrm{a}} \mathrm{M}^{\mathrm{a}} \text { Dolores R. A. c. D. José } \\
\text { Daniel S. M., D. Evaristo A. T. y } \\
\text { "Ocaso SA" }\end{array}$ \\
\hline STS, $1^{\mathrm{a}}, 03.05 .1995$ & RJ 3890 & Teófilo Ortega Torres & $\begin{array}{l}\text { "Catalán Gracia, SA" c. "Frío } \\
\text { Industrial Aragón, SA" }\end{array}$ \\
\hline STS, $1^{\text {a }}, 08.10 .1996$ & RJ 7059 & $\begin{array}{l}\text { Alfonso Barcalá Trillo- } \\
\text { Figueroa }\end{array}$ & $\begin{array}{l}\text { Doña Carmen B. F. c."Guardian } \\
\text { Assurance, plc" y "Sur, SA de } \\
\text { Seguros y Reaseguros" }\end{array}$ \\
\hline STS, $1^{\mathrm{a}}, 07.04 .1997$ & RJ 2743 & Francisco Morales Morales & $\begin{array}{l}\text { D.Josep P. G y otros } 9 \text { c. "Minas de } \\
\text { Potasa de Suria, SA" }\end{array}$ \\
\hline STS, $3^{\mathrm{a}}, 06.03 .1998$ & RJ 2490 & José Manuel Sieira Miguez & $\begin{array}{l}\text { "Sociedad Cooperativa Andaluza" } \\
\text { c."Consejero de Agricultura y Pesca } \\
\text { de la Junta de Andalucía" }\end{array}$ \\
\hline STS, $1^{\mathrm{a}}, 26.07 .2001$ & RJ 8426 & Jesús Corbal Fernández & $\begin{array}{l}\text { D. José Miguel I. c. "Sendero Club" } \\
\text { y "Allianz Ras Seguros y } \\
\text { Reaseguros, SA" }\end{array}$ \\
\hline STS, $1^{\mathrm{a}}, 16.01 .2002$ & RJ 8 & Alfonso Villagómez Rodil & $\begin{array}{l}\text { "Piszolla, SL" c "Unión Eléctrica } \\
\text { Fenosa, SA" }\end{array}$ \\
\hline $\begin{array}{l}\text { SAP Barcelona, } 3^{\mathrm{a}} \text {, } \\
\text { 23.01.2002. }\end{array}$ & ARP 216 & Ana Ingelmo Fernández & "Lípidos Santiga, SA.” \\
\hline STS, $1^{a}, 10.10 .2002$ & RJ 9403 & Alfonso Villagómez Rodil & $\begin{array}{l}\text { Don Iradj G. W c. Don Ignacio y } \\
\text { Don Modesto L.-L. A. }\end{array}$ \\
\hline STS, $1^{a}, 30.10 .2002$ & RJ 9727 & Teófilo Ortega Torres & $\begin{array}{l}\text { D. Francisco c. D. Vicente y } \\
\text { "Vicente Campano, SL" }\end{array}$ \\
\hline STS, $1^{\mathrm{a}}, 06.11 .2002$ & RJ 237 & Jesús Corbal Fernández & $\begin{array}{l}\text { D. José F. B c. "Mota Siderúrgica, } \\
\text { SL" y otros }\end{array}$ \\
\hline STS, $1^{\mathrm{a}}, 27.12 .2002$ & RJ 1332 & Antonio Romero Lorenzo & $\begin{array}{l}\mathrm{D}^{\mathrm{a}} \text {. Sheree M c. "Distribuidora } \\
\text { Industrial, SA" }\end{array}$ \\
\hline STS, $1^{\mathrm{a}}, 25.09 .2003$ & RJ 6826 & Pedro González Poveda & $\begin{array}{l}\text { D. Javier y D }{ }^{a} \text { Encarna c. Servicio } \\
\text { Gallego de la Salud de la Consellería } \\
\text { de Sanidade da Xunta de Galicia. }\end{array}$ \\
\hline STS, $1^{\mathrm{a}}, 27.12 .2003$ & RJ 1332 & Antonio Romero Lorenzo & 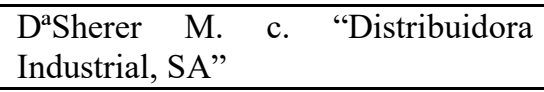 \\
\hline STS, $2^{\mathrm{a}}, 08.11 .2004$ & RJ 7711 & Enrique Bacigalupo Zapater & D. Luis Francisco \\
\hline STS, $1^{\mathrm{a}}, 05.01 .2006$ & RJ 131 & Jesús Corbal Fernández & 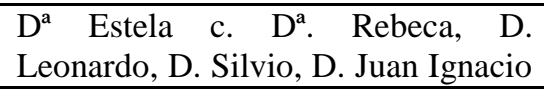 \\
\hline ANUARIO DE DE & 0 CIVIL & TOMO XIII & Página 100 \\
\hline
\end{tabular}




\section{EL PROBLEMA DE LA DETERMINACIÓN DEL NEXO CAUSAL EN LA RESPONSABILIDAD CIVIL POR DAÑOS MEDIOAMBIENTALES: DE LA CERTEZA CAUSAL A LA TEORÍA DE LA CAUSALIDAD COMPLEJA}

\begin{tabular}{|c|c|c|c|}
\hline & & & $\begin{array}{l}\text { y } \mathrm{D}^{\mathrm{a}} \text {. Ángela, D. Clemente y el Ilmo. } \\
\text { Ayuntamiento de Zumaia }\end{array}$ \\
\hline STS, $1^{\mathrm{a}}, 18.07 .2006$ & RJ 4947 & José Almagro Nosete & $\begin{array}{l}\text { D. Jose Ángel c. "Institut Catala de } \\
\text { la Salut", y D". María Dolores }\end{array}$ \\
\hline STS, $1^{\mathrm{a}}, 11.10 .2006$ & RJ 6471 & Pedro González Poveda & $\begin{array}{l}\text { Da Concepción c. "Deporte y Vida, } \\
\text { SA" }\end{array}$ \\
\hline STS, $1^{\mathrm{a}}, 22.02 .2007$ & RJ 1520 & Juan Antonio Xiol Ríos & $\begin{array}{c}\text { D Soledad c. "Restrepo Cacho, SL" } \\
\text { y "La Estrella, Sociedad } \\
\text { Anónima de Seguros y } \\
\text { Reaseguros" } \\
\end{array}$ \\
\hline STS, $1^{\mathrm{a}}, 23.05 .2007$ & RJ 3273 & $\begin{array}{lll}\begin{array}{l}\text { Vicente } \\
\text { Penades }\end{array} & \text { Luis } & \text { Montes } \\
\end{array}$ & $\begin{array}{l}\text { D a Trinidad c. "Hospital municipal } \\
\text { de Badalona" }\end{array}$ \\
\hline STS, $1^{\mathrm{a}}, 23.07 .2008$ & RJ 5509 & Francisco Marín Castán & $\begin{array}{l}\text { Da Antonieta y D. Luis Miguel c. } \\
\text { "Confort Hoteles, SA" }\end{array}$ \\
\hline STS, $1^{\mathrm{a}}, 30.05 .2008$ & RJ4167 & José Almagro Nosete & $\begin{array}{l}\text { "Comercial Unión Española, } \\
\text { Seguros y Reaseguros Generales } \\
\text { SA", c. "Metal alimentaria, SA" y } \\
\text { "Fiatc Mutua de Seguros" }\end{array}$ \\
\hline $\begin{array}{l}\text { SAP Barcelona, } 13^{\mathrm{a}} \text {, } \\
\text { 15.01.2009 }\end{array}$ & JUR 695 & Isabel Carriedo Mompín & $\begin{array}{l}\text { D. Salvador c. D. Luis Antonio y su } \\
\text { aseguradora }\end{array}$ \\
\hline STS, $1^{\mathrm{a}}, 21.05 .2009$ & RJ 3030 & Encarnación Roca Trías & $\mathrm{D}^{\mathrm{a}}$ Tatiana C. "Mapfre Seguros, SA" \\
\hline STS, $1^{\mathrm{a}}, 27.05 .2009$ & RJ 3044 & Juan Antonio Xiol Ríos & $\begin{array}{l}\text { "Eureko Hispania, SA" c. "Price } \\
\text { Waterhouse Auditores, SA." }\end{array}$ \\
\hline STS, $1^{\mathrm{a}}, 19.02 .2010$ & RJ 1287 & $\begin{array}{l}\text { José Antonio Seijas } \\
\text { Quintana }\end{array}$ & $\begin{array}{l}\text { Don Ramón, Don Luis Pablo, Don } \\
\text { Borja y Don Gaspar c. "Iberdrola } \\
\text { Distribución Eléctrica S.A" }\end{array}$ \\
\hline $\begin{array}{l}\text { SAP Vizcaya, Sección } \\
5^{\text {a }}, 28.06 .2011\end{array}$ & JUR 298831 & Magdalena García Larragán & $\begin{array}{l}\text { Doña Tomasa c. “Seguros Santa } \\
\text { Lucia” }\end{array}$ \\
\hline STS, $1^{\mathrm{a}}, 06.02 .2012$ & RJ 4983 & Juan Antonio Xiol Ríos & $\begin{array}{l}\text { "Allianz, S.A-Seguros" y "Dinosol } \\
\text { Supermercados, S.L” c. Don } \\
\text { Eusebio. }\end{array}$ \\
\hline STS, $1^{\mathrm{a}}, 20.10 .2015$ & RJ 4226 & $\begin{array}{l}\text { José Antonio Seijas } \\
\text { Quintana }\end{array}$ & $\begin{array}{l}\text { Asociación de Víctimas de la } \\
\text { Talidomida c. "Grünenthal Pharma, } \\
\text { SA" }\end{array}$ \\
\hline
\end{tabular}

Tabla de jurisprudencia extranjera citada

\begin{tabular}{lcl}
\hline \multicolumn{1}{c}{ Asunto } & Año & \multicolumn{1}{c}{ Referencia } \\
\hline Summers $v$. Tice & 1948 & 33, Cal. 2d 80, 199 P.2d 1. \\
\hline Sindellv. Abbott Laboratories & 1980 & 26, Cal, 3d 588, 697 P 2d 924 y 163. \\
\hline & & STJ, RECURSO ESPECIAL N 327.254 - \\
Recurso Especial no & PR (2001/0064980-4) Relator: Ministra \\
& 2002 & ELIANA CALMON, Data de Julgamento: \\
& & 03/12/2002, T2 - Segunda Turma). \\
\hline
\end{tabular}

